\title{
Number and Gender Convergence: The Arabic Plurative*
}

\author{
Abdelkader Fassi Fehri \\ Mohammed V University Abu Dhabi \& Arabic Language Academy, UAE \\ abdelkaderfassifehri@gmail.com
}

Received: April 10, 2020

Accepted: June 26, 2020

\begin{abstract}
Morpho-syntactic and semantic properties of a specific plural/collective construction in Arabic, which I call the plurative, are examined and analysed. The plurative is shown to be a complex third entity, resulting from a convergence process of both Number and Gender features (and/or categories). It behaves as a syntactic expression denoting groups, which exhibits dual behaviour, licensing plural or single predication, anaphora, or alternating a feminine-singular with a masculine-plural agreement. In its strict sense, the plurative is shown to be both 'one' and 'many', denoting the whole-unity, but also allowing access to the (many) parts. Comparison is made with Slavic group numerals, as well as languages possessing group classifiers like Chinese. The singulative is also argued to be a complex entity, compared to kind collectives and normal singulars. DivP turns out to be too coarse to account for fine individuation differences, and is better split as atomP and unitP.
\end{abstract}

Keywords: plurative; convergence; singulative; group collective; group classifier; group numeral; unitP; atomP; Arabic; Serbo-Croatian; Chinese

\section{Resum. La convergència de nombre i gènere: el pluratiu àrab}

En aquest article s'analitzen les propietats morfosintàctiques i semàntiques d'una construcció plural/col·lectiva de l'àrab, que anomeno pluratiu. S'hi mostra que el pluratiu és una tercera entitat complexa que resulta d'un procés de convergència dels trets (i/o categories) de nombre i gènere. Es comporta com una expressió sintàctica que denota grups i mostra un comportament dual, ja que legitima predicacions $\mathrm{i}$ anàfores singulars o plurals o alterna la concordança femenina singular amb la masculina plural. En aquest sentit estricte, el pluratiu es mostra com 'u' i 'molts' alhora: denota la unitat sencera, però també permet accedir a les (moltes) parts de la unitat. Establim una comparació entre el pluratiu i els numerals de grup eslaus, d'una banda, i les llengües amb classificadors de grup, com el xinès, de l'altra. S'argumenta que el singulatiu també és una entitat complexa que contrasta amb els col·lectius genèrics i els singulars normals. El sintagma SDiv

* I would like to acknowledge helpful remarks and appealing suggestions by two anonymous reviewers of CATJL. For fruitful discussions and comments, thanks are due to Noam Chomsky, Paolo Acquaviva, Peter Hallman, Anders Holmberg, Joseph Emonds, Anna-Maria Di Sciullo, Rita Manzini, Leonardo Savoia, Marcin Wagiel, Jean Lowenstamm, Karimallah Kabbour, and AbdelRahman Altakhaineh. The usual disclaimers apply. 
resulta massa general per donar compte de les subtils diferències en la individualització i és millor dividir-lo en Sàtom i Sunitat.

Paraules clau: pluratiu; convergència; singulatiu; col·lectiu de grup; classificador de grup; numeral de grup; Sunitat; Sàtom; àrab; serbocroat; xinès

\section{Table of Contents}

\section{Morphosyntax}

2. Semantics and architecture

3. Crosslinguistic variation
4. Further motivation and variation

5. Summary and conclusion

References

In this study, I describe (and motivate) a process of Number and Gender convergence in Arabic, whereby a morpheme (homophonous with) feminine gender, - at, is used at various syntactic and semantic configurations to express individuation and/or plurality. ${ }^{1}$ It can be shown that the plurative (a syntactically derived group) is a mode of marking Number and Gender at the same time, where two categories/ features converge to form a complex mixed entity, a specific 'collective', or rather a group individual, with distinct specifications from both normal singular and plural individuals. While Number (as quantity) and Gender (as individuator) are generally viewed as separate categories, each having its own autonomous morpho-syntax and semantics, the idea of convergence in derivation (in Chomsky's 1995 sense) stems from the fact that the two features (or categories) of the syntactic plurative are not interpreted as separate, but rather converge as a complex mixed entity, an entity which is both 'many' and 'one'. Convergence of a similar sort can be shown to operate also in the case of the singulative, although with a distinct outcome, as well as in other kinds of collectives. Furthermore, it can be shown that normal plurals (or numbers) can be turned to plurative (or individuating gender) in syntax, depending on interpretation (or perspectivization). Quite similar grouping (or collectivizing) phenomena are documented in various flavours in other languages (including Serbo-Croation, Polish, Chinese, Burmese, Italian, etc.), instantiating the vastness of crosslinguistic collectivization. Building on some of the diverse previous body of literature, I propose a convergent syntax of the plurative that takes care of its complexity, its polysemy, as well as its converging semantics. Because a group-collective cannot be adequately described as only an atomic individual (as in e.g. Barker 1992), nor as non-atomic individual (or set/sum) just like other plurals (as in Bennett 1974), being a sort of 'impure atom' (Link 1984, 1998; Landman 1989), I propose that it is a unity entity (as a whole), rather than any atom entity. More precisely, two number features are needed to account for the properties of the mixed group, unit and atom, (tentatively) projecting as atomP and unitP. The feature 'unit' stands for unitization (a specific form of individuation) found in sin-

1. The term 'Arabic' is meant to cover the various Arabic varieties, including Modern Standard Arabic (which is chiefly described here), and the colloquials (when specifically referred to). 
gulatives and pluratives (as wholes), and 'atom' basically marks 'natural atoms' (in the parts), normally expressed as singulars and plurals. It is shown that Borer's DivP is too coarse to account for these two distinct ingredients of individuation, or other similar binary specifications, as amply argued in the literature (Svenonius 2008; Grimm 2012; Fassi Fehri 2003-4, 2012; Zhang 2013; Acquaviva 2017, 2018, among others).

Unlike 'lexical' groups, which may trigger a singular/plural alternation, without 'gender switch', Arabic (syntactic) pluratives or groups typically involve Gender unitization in syntax. While Number as a grammatical category is normally conceived as essentially expressing specified quantity, distinguishing atoms and sums, morphologically identified as singulars or plurals, the more complex picture reflects the ways entities are 'classified' or 'qualified' (as objects, kinds, masses, groups, etc.), in addition to how Number interacts with numerosity, mereological relations among sets, etc. Arabic contributes a large variety of ingredients and patterns that enrich our understanding of Number, and how it is expressed in various languages. More specifically, Arabic belongs to the class of so-called collective-singulative languages, where a singular can be formed out of a 'collective' (or general/kind base), by singulative morphology, and pluratives are (normally) formed from collective or plural bases (Wiese 2012). The resulting 'group collectives' (Leisi 1971; Mihatsch 2015) are then unities, and can be hardly analyzed as atomicities, only denoting a restricted set of non-atomic (or plural) entities. They are rather constructing a unity over a plurality in the grammar, using a unity suffix.

The article is organized as follows. In Section 1, I describe a tripartite morphological plural system for Arabic, whereby the plurative is introduced as a form of plural, in extension to the more traditional dual sound/broken system. I also compare essential properties of the plurative uses as a non-atomic plural to the individuator uses, and discuss some mixed behaviours of the other plurals. In Section 2, I examine the semantics of atoms, unities, and groups, as well as the syntactic architecture of pluratives and singulatives. Section 3 is dedicated to some relevant crosslinguistic instantations and variations of expressions of syntactic group numerals and nominal collectives across Serbo-Croatian, Polish, Burmese, and Chinese. Section 4 provides further motivation of convergence in analysing pluratives, singulatives, or more collectives of various types, and it extends the description to Czech group numerals, Italian aggregates, as well as broken and other forms of Arabic plurals. Section 5 summarises and concludes.

\section{Morphosyntax}

To set the stage, let us start with some morphological and syntactic properties of plurals, by comparing behaviours of the more standard 'sound' and 'broken' plurals to those of the plurative. I then provide 'gender' properties of the plurative individuator, and more precisely its unitizer syntax, compared to its plural syntax. Subsection 1.5 and 1.6 provide illustrations of group, sound, and broken plural constructions involved in alternating unitizer and plural syntax. 


\subsection{Three morphological plurals?}

\subsubsection{Sound number}

Sound number is marked uniformly by a suffix on nouns, adjectives, verbs, and pronouns. It is the most transcategorial morphological number. In (1b \&c)), dual and plural are marked on a noun (or adjective), compared to the singular in (1a), which is a default (or unmarked), and in (2), number marking is on verbs:

(1)
a. kaatib (-un)
'1 writer'
b. kaatib-aa (ni)
'writer-dual'; '2 writers'
c. kaatib-uu (na)
'writer-pl'; '>1, or $>2$ writers' (strong reading)

(2) a. katab-a

'he wrote; he is 1'

b. katab-aa

'they wrote; they is 2 '

c. katab-uu

'they wrote; they is $>1$, or $>2$ '

\subsubsection{Broken number}

Broken number is 'defective' in the sense that it applies only to nouns (or adjectives), and only (internal) plurals (to the exclusion of duals). In (3), a broken plural parallels the sound counterpart found in (1c):

(3) kuttaab (-un) " $>1$, or $>2$ writers"

As for the dual, only a sound form is used, with no broken variety, as in (4):

(4) fii d-daar-i kaatib-aani

in the-house-GEN writer-DUAL.NOM

'There are two writers in the house'.

The relevant interpretation is then that in (4), there are 'two' writers in the house (and no more). In (5a), there is 'one' writer (and no more), in (5b) there is 'more than one', or 'more than two' (by contrast with (4)):
a. fii d-daar-i
kaatib-un
in the-house-GEN writer-NOM
'There is a writer in the house.'
b. fii d-daar-i kuttaab-un
in the-house-GEN writer-PL.NOM
'There are writers in the house'.

These nouns denote either single atoms, or sums (or sets) of atoms, respectively, but are not set free to denote atoms or sums (except when the plural in (5b) is inclusive, in addition to being possibly exclusive). The sound/broken variation is often 
thought as only morphological, i.e. as whether plural marking is a sound concatenative suffix (added to the stem, or an 'external plural'), or an 'internal' broken vowel affix, as instantiated in (3). But the distinction has more syntactic and semantic peculiarities when we think of it in terms of Number, rather than just plural.

\subsubsection{Plurative number}

A third form of the plural, often neglected, although quite productive, which I want to identify and establish, is the plurative (= plv). It is illustrated in (6): ${ }^{2}$

\section{(6) kaatib 'writer' $\rightarrow$ katab-at writer-PLV.NOM; 'writers'}

This plural is characterized by its homophonous feminine ending -at, which makes it essentially 'sound' (although it often mixes with broken morphology in largely unpredictable ways). The plurative form can function as normal plural, but in the most relevant contexts, it is often interpreted as a group. One essential syntactic difference between the plural and the plurative construction is the nature of agreement involved. In the plurative (7), the verbal predicate agrees with the subject in the feminine ('singular'), while it agrees in 'masculine' plural with the sound plural in (8), depending on interpretation:

(7) 1-qatal-at-u xtaba?-at

the-killer-PLV-NOM hid-PLV

'The killers (as group) hid.'

\section{(8) 1-qaatil-uu-na xtaba?-uu \\ the-killer-PL.NOM hid- PL \\ 'The killers hid.'}

In (7), the subject is interpreted as a group, the plurality being perspectized as a unity, and the predicate is a grouped event or action. Both constituents are then marked as 'feminine', the mark of unity in the language. In (8), both the subject and the event are interpreted as sums of individuals or events, and they are marked as plural masculine. What is striking, though, is that the consistently transparent plurative in (7) can alternate with a plural use in which the predicate is not read as group, but as a normal plural event, as illustrated in (9):

2. The term 'plurative', as I use it, designates the morphosyntactic counterpart of the 'singulative'. It forms a specific plural entity, distinct from normal plurals, which is characterized by its unity (as a whole), in parallel to the singulative, which builds a specific singularity, also as characterized by unity (or unit), and distinct from normal singulars. This use of the term is somewhat different from its use in the Africanist literature, where it usually designates a process by which a strong or distributive plural is derived from a base that is a general noun (see Mous 2008). Corbett (2000: 17, fn. 11) situates the term with respect to the singulative as follows: "If one uses 'singulative' consistently for singular forms which correspond to a more basic plural form, then it would be logical to use the term 'plurative' for plural forms which correspond to a more basic singular, as in ker 'dog' $\sim$ ker-o 'dogs' [from the Cushitic language Arbore], as [originally] suggested by Dimmendaal (1983: 224)." See also fn 31 for another innovative use. 
(9) 1-qatal-at-u xtaba?-uu

the-killer-PLV.NOM hided- PL

'The killers hided.'

How can a plurative have a double use (as plural in addition to plurative) will be explained below. Note that both singular and masculine are only defaults, with absence of marking. A sample of various plurative forms (which normally denote groups) is given in (10):

(10) a. najjar 'carpenter' $\rightarrow$ najjaar-at 'carpenters (as group)'; haddaad 'blacksmith'

$\rightarrow$ haddaad-at 'blacksmiths (as group)';

b. sakiin 'inhabitant' $\rightarrow$ saakin-at; baa?iৎ 'seller' $\rightarrow$ baaS-at 'sellers'; saadin 'guardian'

$\rightarrow$ sadan-at 'inhabitants'; taag-in 'tyran' $\rightarrow$ tug-aat 'tyrans'; haamin 'protector'

$\rightarrow$ hum-aat 'protectors'; xaa?in 'traitor' $\rightarrow$ xawan-at 'traitors', etc.

c. sunn-ii 'sunni' $\rightarrow$ sunn-at 'sunnis'; šii $-i i$ 'shiite' $\rightarrow$ šii -at 'shiites'; majuus-ii 'magian' $\rightarrow$ majuus-iyy-at 'magians', etc.

Note that the list includes a diversity of the nominal bases from which the plurative is derived that I will return to below.

Triplets or doublets of plurals are found, with some subtle or specific meaning differences in some cases, and interchangeable forms in many others (groups, plurals, evaluatives, etc.; see Fassi Fehri 2016). When distinctions between various unmarked or marked singulars enter the picture in forming plurals of various kinds, the syntax of number becomes necessary, to distinguish 'lexical' or $n$ plurals (Acquaviva 2008) from number or \# plurals, head and modifier plurals, or plurals of atomicities and plurals of unities, etc. (see Fassi Fehri 2018 for detail).

Apart from their productivity, the alternations of these kinds of plurals pose challenging problems in terms of their morphology, syntax, and semantics. I will concentrate in the next sections on the plurative, when compared to other plurals, but also to singulatives and singulars. In practice, the sound plural appears to have a rather limited distribution, compared to the broken plural (in addition to the plurative), and they are often in complementary distribution, rather than being in competition. The sound masculine plural is further (often) restricted to masculine nouns referring to rational beings. But broken pluralization is also qualitatively productive as first shown by McCarthy \& Prince (1990). In sum, both sound and broken pluralization are subject to a host of conditioning factors that make them qualitatively productive in applying to a particular singular (Boudelaa \& Gaskell 2002; Ratcliffe 2011, among others). ${ }^{3}$

3. As McCarthy \& Prince (ibid: 212) observe, “ “... essentially all canonically-shaped lexical nouns of Arabic take broken plurals", while the sound plural is "systematically found only with the 


\subsection{Plural syntax}

Two syntactic properties of plurals are the most significant, in contexts where only plurals can occur, although interpreted differently.

\subsubsection{Sum plurals triggering predicate agreement in Gender and Number}

All plural forms can occur in syntactic contexts where they (undifferentially) control predicate agreement in number and gender, as in the following examples:

(11) fii 1-madrasat-i mudarris-uuna ?akfaa?-u

in the-school-GEN teacher-PL.NOM competent.PL-NOM

'There are competent teachers in the school.'

(12) ț-țullaab-u ḥadar-uu

the-students-NOM came-PL

'The students came.'

(13) $\mathrm{s}-\mathrm{s}$
s-sadan-at-u
šaddad-uu 1-ḥiraasat-a
the-guardians-PLV-NOM reinforced- PL the-guarding-ACC
'The guardians reinforced the security.'

In (11), a sound masculine plural controls a masculine plural on the adjective. In (12), a broken plural controls a masculine plural on the verb, and in (13), it is a plurative form that does so. All these plurals provide bases for interpreting the DP controller as sum, Number being generated under \#P, the locus of quantity phrases, as in Borer (2005), or under NumP, as in Ritter (1991). The plural marker on the predicate is uninterpretable, being only a formal agreement marker (or feature), as in standard cases of Agree (Chomsky 1995).

\subsubsection{Numeral agreement}

Another diagnostic to test the plural behaviour of the three plural forms is when they all (undifferentially) occur as a complement of a low numeral in numeral (modifying) constructions. In the following examples, a broken plural, a sound plural, and a plurative are all constructed with low numerals:

(14) talaat-at-u țullaab-in

three-FEM-NOM students-GEN

'Three students'

following short list: proper names; transparently derived nouns or adjectives such as participles, deverbals and diminutives, non-canonical or unassimilated loans ...' Contrary to the (sound) dual number which basically applies to any noun or adjective, the sound plural is restricted to a set of nominal forms that must meet formal and syntactic criteria, and although restricted as such are 'qualitatively productive'. Boudelaa \& Gaskell (ibid: 326 ) claim that the sound plural is "the quantitatively productive pluralisation process", but even if this were true of the system as a whole, their statistics do not mirror the fact that sound plurals of nouns are rather limited in number, proper names and participles aside. 
(15) talaat-u țaalib-aat-in yamaniyy-aat-in

three-NOM student-FEM.PL-GEN yemeni-FEM.PL-GEN

'Three female Yemeni students.'

(16) talaat-at-u sadan-at-in

three-FEM-NOM guardian-PLV-GEN

'Three guardians'

Typical of these contexts is the fact that the numeral is counting singular objects, rather than plural individuals, in the genitive complement. Note that the genitive on the noun complement is required by the numeral.

It is then reasonable to think of the plural there as a formal agreement marker, rather than an interpretable plural (Krifka 1989; Borer \& Ouwayda 2010). Thus the plurative in this context cannot be interpreted as a group, because (single) lexical groups are excluded in this context, just as general 'collectives' are, hence the ungrammatical (17) and (18), where the collective is in the singular (and its parts cannot be counted):

$$
\begin{aligned}
& \text { (17) * talaat-u Pusrat-in } \\
& \text { three-NOM family-GEN } \\
& (18) * \text { talaat-at-u samak-in } \\
& \text { three-FEM-NOM fish-GEN }
\end{aligned}
$$

Although groups like ?usrat are (directly) countable as units (while general collectives are not), they are rejected in this context because they are not pluralized. ${ }^{4}$

In high numeral contexts, however, in which only singular nPs are allowed, the plurative (unlike other plurals) can be counted as a group, just like other singular groups. Compare (20) to (19), where counting groups as singulars is fine (note that $-u u$ suffixed to the unit numeral forms tens):

(19) talaat-uu-na Pusrat-an

three-PL-NOM family-GEN

'Thirty families'

(20) talaat-uu-na sadan-at-an

three-PL-NOM guardian-PLV-ACC

'Thirty goups of guardians'

4. Indeed, the pluralized cases are fine, as in (i) and (ii):

(i) talaat-u Pusar-in three-NOM family.PL-GEN 'Three families'

(ii) talaat-at-u Pasmaak-in three-FEM-NOM fish.PL-GEN 'Three fish(es)' 
In contrast, recall that the parts of the general/kind collective can be indirectly counted, as in (21), but cannot be directly counted as such, as in (22); only a kind/ taxonomic counting is possible here:

(21) Gadad-tu s-samak-a fa-wajad-tu Gišriina counted-I the-fish-ACC then-found-I twenty 'I counted the fish, and found twenty.'

$(22) \neq$ Yadad-tu Gišriina samak-an counted-I twenty fish-ACC

'I counted twenty (units of) fish.'

In sum, the plurative exhibits a dual behaviour in the context of numerals. It is counted like singular individuals in the context of low numerals, or like singular groups in the context of high numerals. In the next subsection, I provide more justification for taking the plurative as a unitizer of a specific sort, or a group classifier. $^{5}$

\subsection{Unitizer syntax}

Fassi Fehri $(2016,2018)$ has argued that Arabic uses various modes of functional or semi-functional categories to express classification, or more specifically various forms of unitization, parallel to those found in well-known classifier languages (such as Chinese, Japanese, Thai, etc.). These modes typically include feminine Gender, and semi-functional pseudo-partitives, where sortal and group classifiers are used, in addition to mensural classifiers.

\subsubsection{Arabic as a 'classifier language'}

Arabic is not only a 'number' language, in the descriptive sense that it has an elaborate (and compulsory) Number morpho-syntax (even more complex than that of Germanic or Romance), or a 'gender language' (distinguishing various grammaticalized feminine/masculine contrasts), it can also be seen as a 'classifierlanguage' (a not-so acknowledged property), in view of its uses of classification marking morphemes (or classifiers), in addition to other classifying devices. ${ }^{6}$ Most salient types of classifiers in known classifier languages are (a) sortal classifiers,

5. Note that the general/kind collective supports reciprocity, as in (i), strongly suggesting that its parts (or individual atoms) are visible in syntax, and hence cannot be analyzed like mass:

(i) s-samaku ya?kulu bałḍ-u-hu bąḍ-an

the-fish-NOM eats some-NOM-his some-ACC

'The fish eats each other.'

It is clearly different from syntactically mass nouns like Pataat 'furniture', or silverware in English, which do not allow such syntactic accessibility. Other properties of distinct pluralities are discussed in Fassi Fehri (2016, 2018), including plural predication, reciprocity, plural anaphora, etc.

6. Other devices include the use of semi-lexical nouns like ra?s 'head', or pseudo-partitive structures, as I will explain below in this section. 
and (b) mensural (measure) classifiers. Sortal classifiers can be further divided into unit classifiers, and group classifiers (Lyons 1977; Allan 1977; Aikhenvald 2000; Rijkhoff 2002; Beckwith 2007; Fassi Fehri \& Vinet 2007; Gil 2013, among others). Lyons (1977: 463) explains that a sortal classifier “... individuates whatever it refers to in terms of the kind of entity that it is", while a mensural classifier '... individuates in terms of quantity' (emphasis mine). Aikhenvald (2000: 115) observes that "sortal classifiers categorize nouns in terms of their inherent properties such as animacy, shape, consistency [... whereas] mensural classifiers are used for measuring units of countable and mass nouns [... as] conditioned by two factors: the quantity, or measure, of an entity, and its physical properties". Krifka $(1989,2013)$ and Scontras (2014) identify three distinct 'quantizing' expressions (or countables): (a) measure terms (e.g. kilo, inch, pound), (b) container nouns (e.g. bottle, glass, box), and (c) atomizers (e.g. grain, piece). These two main kinds of classifiers have (directly or indirectly) motivated the projections of sortP and unitP in the grammar (Svenonius 2008).

\subsubsection{Arabic Unit Classifiers}

Arabic unit classifiers for singular entities come in the form of semi-lexical (or semi-functional) nouns meaning ra?s 'head', fașs 'clove', qițat 'piece', nafs 'self', etc., which are directly counted by the numeral, instead of counting the main noun denoting the object, as in the following normal numeral expressions:

(23) xams-at-u ru?uus-i baqar-in

five-FEM-NOM heads-GEN cows-GEN

'Five heads of cattle'

(24) xams-at-u fușuuṣ-i țawm-in

five-FEM-NOM cloves-GEN garlic-GEN

'Five cloves of garlic'

(25) xams-u qițaf-i samak-in

five-NOM pieces-GEN fish-GEN

'Five pieces of fish; five fish'

In these possessive genitives, the main noun (or nP) is uniformly bare, it denotes a kind or mass, but it is crucially not singular. A hidden preposition $\min$ (meaning 'part of' or 'from') is normally postulated by Arabic traditional grammars in their structure, and the construction interpreted as a sort of pseudo-partitive. Note that the genitive morphological case on the mensural classifier is required by the numeral, rather than by the pseudo-partitive itself.

Alternatively, the semi-functional noun heads an overt pseudo-partitive structure, which manifests the preposition $\min$, as in (26a \&b): 
(26) a. xams-at-u ruPuus-in min baqar-in

five- FEM-NOM heads-GEN of cows-GEN

'Five heads of cattle'

b. xams-at-u fușuuș-in min tawm-in

five- FEM-NOM cloves-GEN of garlic-GEN

'Three cloves of garlic'

These alternating Arabic synthetic or analytic partitives/genitives are closer to English pseudo-partitives than they are to partitives, and they represent a semilexical mode of classification in Arabic, close to unit classifier constructions in non-disputably classifier-languages such a Chinese (see Fassi Fehri 2018 for detail).

In parallel, Arabic has another mode for expressing unities, or unitization, namely the functional mode of Gender. The feminine suffix - at, identified in the literature as a singulative, plays an individuative role and acts as a classifier, as Greenberg (1972) and others have observed (Ojeda 1992; Fassi Fehri 2003-04, passim; Zabbal 2002-05; Mathieu 2012). Feminine gender morphology is then seen as an alternative mode of expression to the semi-functional head in the analytic pseudo-partitive constructions analysed above, and at the same time to the classifier in South Asian languages. Consequently, the 'indirect' noun-headed counting constructions in (23)-(26) above can be replaced by 'direct' counting noun constructions, where a functional Gen(der) suffix, in fact a classifier unit affix is added to the lower counted noun, to make it directly countable, as in the following examples using high numerals:

(27) a. xams-uu-na baqar-at-an

five-PL-NOM cows-UNIT-ACC

'Fifty cows'

b. xams-uu-na tawm-at-an

five-PL-NOM garlic-UNIT-ACC

'Fifty garlics'

As for low numerals, the direct functional counterparts also have a classifier UNIT affix, although it is also plural, for agreement purposes:

(28) a. xams-u baqar-aat-in

five-NOM cow-UNIT.PL-GEN

'Five cows'

b. xams-u tawm-aat-in

five-NOM garlic-UNIT.PL-GEN

'Five garlics'

c. talaat-u samak-aat-in

five-NOM fish-UNIT.PL-GEN

'Five fish(es)' 
If so, then the -at suffixed in (27) and (28) on the noun baqar 'cow', for example, plays basically the same role as the semi-lexical noun ra?s 'head' in (23) or (26). The two patterns are just two modes of classification, or more precisely unitization. Traditional Arabic grammarians (as early as the $8^{\text {th }}$ century) first pointed out that the role of the feminine suffix is to form ism wahd-at 'a unit noun', or a 'nomen unitatis', derived normally from a general kind base ism jins 'noun of species' (see e.g. Sibawayhi, $8^{\text {th }}$ c.; Suyuutii, $15^{\text {th }}$ c., among others; also Wright, 1971). This essential insight inspired lately most authors cited. But relating the two modes of classification is my own.

\subsubsection{Group classifiers}

Like sortal unit classifiers discussed earlier, group classifiers of the semi-lexical mode are similarly placed in genitive or pseudo-partitive contexts. Thus the genitive construct states in (29) have parallel prepositional pseudo-partitive alternants in (30):

(29) a. qațiis-u ganam-in

herd-NOM sheep-GEN

'A herd of sheep'

b. baaqat-u ward-in

bunch-NOM rose-GEN

'A bunch of roses'

(30) a. qațiis-un min ganam-in

herd-NOM of sheep-GEN

'A herd of sheep'

b. baaqat-un min ward-in

bunch-NOM of rose-GEN

'A bunch of roses'

These constructions can be analysed in a way similar to that motivated for the semi-functional unitizers above, with the same basic properties, except that the head of the construction comes from another list of 'lexical' nouns, namely 'group', 'community', 'collection', 'band', 'troop', 'herd', 'drove', 'flock', or whatever terms name a group property. The analytic form of these group unitizers (or their semi-functional mode) has been exemplified above by genitive construct-states or prepositional pseudo-partitives.

A 'synthetic' alternative to the 'analytic' group classification in functional morphology comes in the form of what I term the plurative. The latter has the same morphological form (the suffix - at) as the singulative, but it has a different syntax and semantics. A straightforward instantiation of the morphological plurative as an alternative to the group classifier in (31a) is provided in (31b): 
(31) a. jamaaSat-un min buudiyy-iina

group-NOM of buddhist-PL-GEN

'A group of Buddhists'

b. 1-buudiyy-at-u

the-buddhist-PLV-NOM

'The Buddhists (as a community)'

The behaviour of the 'sortal' group classifier in (31), which provides both a semi-functional and functional mode in (31a) and (31b) respectively, contrasts strikingly with that of mensural (or measure) pseudo-partitive, exemplified in (32). The latter instantiates only a semi-lexical mode, which has no 'direct' functional mode counterpart:
(32) štaray-tu rițl-ayni
$\min$ Sasal-in
bought-I pound-DUAL.ACC of honey-GEN
'I bought two pounds of honey.'

\subsection{Functional and semi-functional structures}

The subsection provides two equivalent structures for classifier expressions in the wide sense used above. One involves a semi-functional pseudo-partitive, and the second makes use of unitizing Gender as a functional category, in fact a UNIT classifier.

\subsubsection{The semi-functional pseudo-partitive}

Starting at least with Selkirk (1977), it was undisputedly assumed that the partitive and the pseudo-partitive constructions represent two distinct syntactic structures, the partitive consisting of two separate DPs. In contrast, a mono-phrasal analysis of classifier phrases is more motivated for pseudo-partitive constructions in (26). Inspired by Stickney (2010) and Keenan (2013), I propose that the structure of construction (26b) is basically as follows (Nmr is for Numeral; Unit is used as the measure head of the pseudo-partitive; UnitP is a projection of the classifier phrase, equivalent to (but more precise than) Borer's DivP; a pseudo-PP is introduced for simplification, instead of Stickney's and Keenan's FP, paralleling the more contentful PP of the partitive containing a DP):

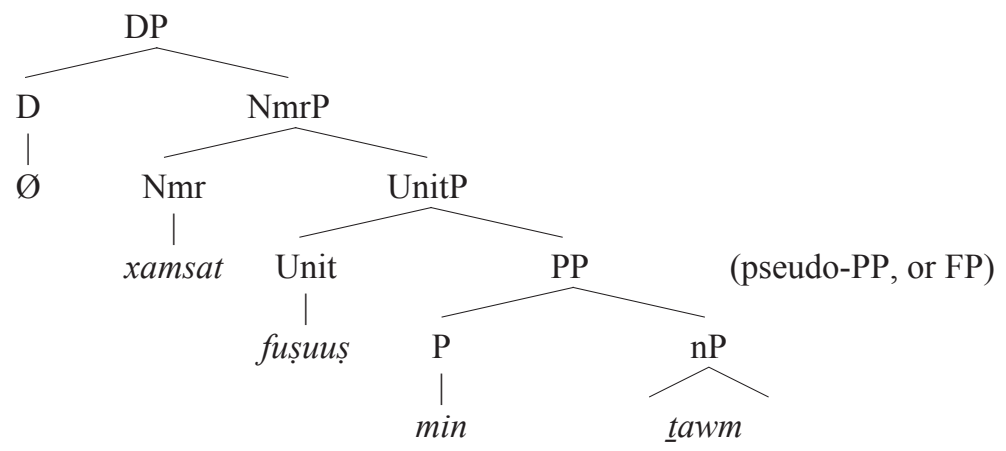


This structure differs substantially from its partitive counterpart. Instead of a fully nominal or lexical nP, the unitizer phrase UnitP (equivalent to the more general measurement MP of Keenan 2013; or Scontras 2014) contains what would have been the 'part' and the 'whole' in the partitive structure. Its Unit head is semifunctional, and the functional pseudo-PP (or FP) parallels the fully lexical PP in the partitive.

Consider now the case of genitive or pseudo-partitive group classifiers in constructions like (29) or (30), respectively. Their structure is basically similar to that of (33) in being a pseudo-partitive structure, although the unitizer here is a GROUP. I use GroupP for the sake of marking the distinction, although both pluratives and singulatives are unitizers, in fact projecting UnitP. The structure of the pseudo-genitive in (29b) is then as in (34), where KP (a case phrase) has been introduced instead of the PP in pseudo-partitive, and the nP moves there for case reasons:

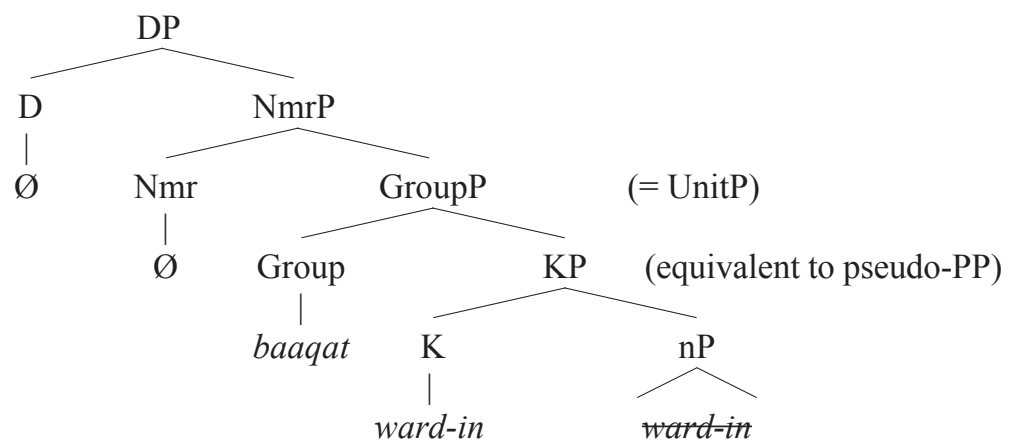

\subsubsection{Functional singulatives and pluratives}

Consider now what would be the functional counterparts to the semi-functional (33) and (34) in terms of the functional mode of unitization. As explained earlier, the functional parallel to (33) is the singulative construction, and the functional parallel to the semi-functional (34) is the plurative, as the best candidate.

Let us look first at how the singulative structure mirrors that of the semifunctional singular pseudo-partitive. Equivalent to fușuus min tawm-in 'cloves of garlic' in (33) is tawm-aat in (35). It is formed by merging the noun with the unitizer affix (in the form of the feminine), in addition to pluralizing it (via vowel lengthening) for agreement purposes with the numeral. The plausible structure of the singulative is then as in (35) (where Nmr for numeral and Num for Number, are kept separate): 


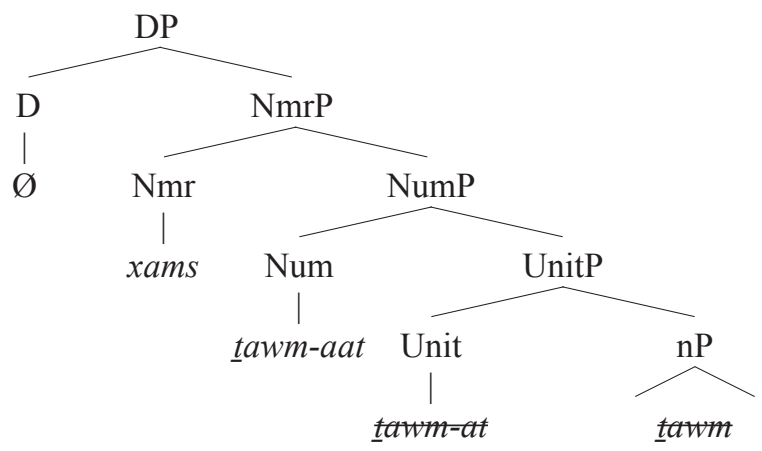

Therefore (33) and (35) appear to be almost identical, the pseudo-PP in (33) aside. $^{78}$

Let us turn now to the case of groups, which are also formed via Gender morphology, and specifically those that I have termed pluratives. I will look at cases that are well-formed pluratives, the formation of which could parallel that of (34). The form ward-at is potentially a candidate, but it is a singulative of ward, meaning 'one rose', rather than plurative, 'a group of roses'. Why is this so? It seems that animacy (or even humanness) is a constraint on pluratives, just it is a constraint on forming another form of singulatives with -ii as exemplified in (36), where both the human plurative and the human singulative are derived from a hypothetical (unlexicalized) collective $*$ sunn $($ plurative $=$ plv; singulative $=$ sgv):

(36) a. *sunn 'sunnite' $\rightarrow$ sunn-at sunnite-UNIT ${ }_{\mathrm{PLV}}$; 'sunnites as a group'

b. *sunn 'sunnite' $\rightarrow$ sunn-ii sunnite-UNIT ${ }_{\mathrm{SGV}}$; 'a sunnite'

But lexicalized pairs of general/kind collectives and group collectives are found, as has been established in (10b) above, where a derivational relation can be established. Such a pairing is illustrated in (37):

(37) sadan 'guardians' $\rightarrow$ sadan-at 'guardians as group'; kafar 'unbelievers' $\rightarrow$ kafar-at 'unbelievers as group'

7. In fact, they can be fully identical once a KP is introduced in both the genitive structure in (33) and the pseudo-partitive in (31), instead of PP. Due to lack of space, I will not elaborate on the matter here. For more subtleties on peuso-partitives, see Stickney (ibid), Keenan (ibid), and Arsenijević (2006), among others. For a more fine-grained structure of Arabic numerals, see Zabbal (2005), Ouwayda (2014), and Fassi Fehri (2018).

8. UnitP (dedicated to individuation) is tentatively separated from NumP (for quantity), and NmrP (for numerosity) is kept distinct from NumP. The literature has various abundant combinations (or fusions) of these categories that I will not discuss here, although they have received attention in the relevant references previously mentioned. Units or unities can be pluralized as is the case of the plural of singulatives or groups. Numerals in Arabic are heads, rather than specifiers, so there is a sense in which Nmr can be higher than Num, as in (33). 
If so, the kind collective (as a base) is unitized by - at to form a group collective, as in the structure (38), which parallels the lower structure of the semi-functional group phrase (34) (KP being absent here):

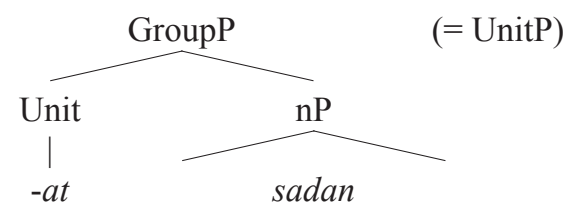

In this structure, the $n$ and the group classifier merge to form a plurative UnitP. As also illustrated earlier, there are pluratives that derive from singulatives, as in (31b) above. The derivation then involves repetition of unitization, where the plurative is higher than the singulative. Consider the potential derivational steps in (36), in which a collective base derives a singulative, and the new formed noun derives a plurative:

(39) majuus 'magians' $\rightarrow$ majuus-ii 'magian-UNIT'; 'a magian'

$\rightarrow$ majuus-iy-at 'magian-UNIT-GROUP'; 'magians as group, community'.

In the following construction, the formed plurative controls classifier agreement, the 'feminine':
(40) 1-majuusiy-at-u
ittafaq-at Salaa haadaa
the-magian-UNIT-NOM agreed-UNIT on this
'The Magians (as a community) agreed on this'.

Two forms of plurals/pluralities are possible to mean 'magians', and both are derived from the singular/singulative majuus-ii. The 'normal' plural is the sound plural majuusiyy-uu-na, derived by suffixing the long vowel -uu to the singulative majuus-ii. But a plurative can also be formed by suffixing the group/unit classifier -at. Thus the relevant plausible structure of this kind of plurative, with its relevant reading, is as follows, instantiating a double unitization:

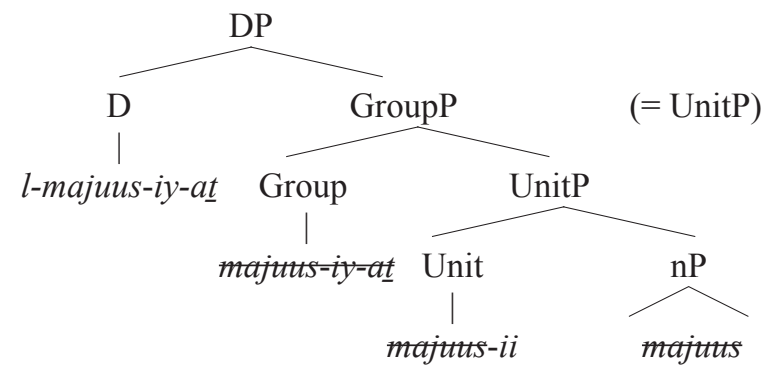


If so, then the plurative can select singular or singulative forms as its derivational base, although it is semantically plural. ${ }^{9}$ It can also select plurals. ${ }^{10}$ Then the structure (41) is built on two classifiers, or two unitizers, one over the other on the same nP, although with distinct meaning contributions, the lower building a singularity, and the upper a plural unity. What is important to note is that there is a strict parallel between the singulative functional structure in (35) and the semi-functional structure of the classifier construction in (33). Likewise, there is strict parallel between the semi-functional structure of the group phrase in (34) and the functional structure of the plurative in (38), or (41), although the latter appears to be more complex. ${ }^{11} 12$

\subsection{Group nouns alternate like pluratives}

Although 'lexical' group nouns are not treated like pluratives in numeral contexts, they often behave like pluratives in contexts of predicative agreement. For example, some lexical groups like those given in (42) can control either plurative agreement, as exemplified in (43) and (44), or plural (sound) agreement, as in (45):

9. Strictly speaking, it is not true that majuus-ii 'magian' is a singular individual; it is only so by default, by contrast with the dual majuus-iy-aa-ni, the sound plural majuus-iy-uu-na, or the plurative majuus-iy-at. It is plausible to think that the individual base as a set noun (in the sense of Rijkhoff 2002), and that it is 'coerced' to be singular in the case of the dual or the plural of the singular, while it is construed as a kind collective 'plural' in the case of the plurative. Recall that the simple kind collective majuus can express plurality as well, meaning 'magians'.

10. As correctly pointed out by a reviewer, it is hardly incidental that the kind collective majuus 'can express plurality', as previously mentioned in fn. 9. It is not just equivalent to an English bare plural in its generic reading, neither plausibly regarded as a morphosyntactic singular (as in old-fashioned English forms like the Magian is learned = 'Magians are as a rule learned'). What is crucial is that the kind collective, unlike a kind denoting singular, can support reciprocal anaphora, for instance, as pointed out in fn 5 . The asymmetry is then worth noting, precisely because not only a plural/ singular dichotomy of the more common type can be observed for supporting generic/kind readings in Arabic (as found in Germanic, Romance, Brazilian Potuguese, etc; see Mari, Beyssade \& Del Prete 2013 for variation patterns and references), but also a third type akin to kind collectives. See also subsection 4.1.1. below.

11. Note that using 'small' $n$ (or nP), instead of the functor projections UnitP or GroupP (as in found in Lowenstamm 2008, or Kramer 2015, among others), does not help in clarifying the appropriate (grammaticalized) functional structure involved.

12. In Fassi Fehri (2012), properties of various collectives and groups are discussed. Properties of general/kind collectives include namely the following:

(i) they are (indirectly) countable;

(ii) they denote one or more discrete atomic entities;

(iii) they have the singulative property; that is, they can be derivationally related to their atomic singularities.

As for group collectives (or syntactic groups) their salient properties include:

(i) they control a uniformly collective ('feminine') marker;

(ii) they are (normally) formed from an already plural nominal;

(iii) they exhibit ambiguity with reciprocals;

(iv) they resist generally further pluralization. 
(42) naas 'people'; turk 'turks'; furs 'persians'; Sarab 'Arabs'

(43) t-turk-u t-ufaawiḍ-u l-furs-a the-Turk-NOM UNIT-negotiate-NOM the-Persian-ACC 'The Turks (as group) negotiate with the Persians.'

(44) 1-Yarab-u mutaraddid-at-un tujaaha 1-harb-i the-Arab-NOM undecided-UNIT-NOM as-to the-war-GEN 'The Arabs (as a group) are undecided vis-à-vis the war.'

(45) t-turk-u laa y-uriid-uuna 1-harb-a the-Turk-NOM not 3-want-PL the-war-ACC 'The Turks do not want the war.'

Note that the unity of such groups is also confirmed by their ability to control a dual feminine agreement:

(46) 1-furs-u wa t-turk-u ta-ta-faawad-aani the-Persian-NOM and the-Turk-NOM UNIT-REC-negotiate-DUAL 'The Persians and the Turks (as groups) negotiate with each other.'

Other lexical groups cannot be plurative (e.g. ša $a b$ 'people, nation', fariiq 'team', rakb 'riders', sahb 'companions'), hence the ungrammaticality of (47):

(47) $r$-rakb-u mutaraddid-uuna (* mutaraddid-at-un) the-riders-NOM undecided-PL.NOM (* undecided-UNIT-NOM) 'The riders (* as group) are undecided vis-à-vis the war.'

Likewise, dual non-plurative groups are found only with masculine duals:

(48) 1-fariiq-aani ya-ta-faawaḍ-aani (* ta-ta-faawaḍ-aani) the-team-DUAL.NOM 3-REC-negotiate-DUAL (UNIT-REC-negotiate-DUAL) 'The two teams negotiate with each other.'

\subsection{Broken and sound plurals alternate as pluratives}

Broken plurals can alternate as pluratives, and hence control feminine singular agreement, as in the following construction:

(49) r-rijaal-u mutaraddid-at-un (mutaraddid-uuna)

the-men-NOM undecided-UNIT-NOM (undecided-PL.NOM)

'The men (as group) are undecided'.

They also license feminine singular anaphora, as in (50): 
(50) hiya r-rijaal-u (hum)

she the-men-NOM (they)

'It is men (as group)'.

As for sound plurals, they behave also alike, in a number of documented cases, where they control either feminine anaphors, as in (51), or feminine singular agreement, as in (52): ${ }^{13}$

(51) 1-muslim-uuna ḍamma-haa l-jumaS-u

The-moslems-PL.NOM gathered-SHE the-Fridays-NOM

'Moslems (as group) were brought together by Fridays'.

(52) bi-mabSat-i-hi kull-u n-nabiyy-iina baššar-at

with-mission-GEN-HIS all-NOM the-prophet-PL.GEN preached-GROUP

'All prophets (as group) announced his mission' (Mohammad's mission, the prophet).

It appears then that when it comes to predicate agreement or anaphora, pluratives and other plurals become equal in allowing feminine singular, instead of masculine plural. What is important to note, however, is that this variation in agreement or anaphora does not come for free. It rather correlates with a meaning change. Plurals are then 'perspectivized' as expressing UNITY of the plurality (i.e. expressing GROUP), rather than distributed or scattered multitude of individuals. In this sense, the specific plurative meaning appears, on the one hand, close to that of the singulative (another morpho-syntax which is associated with the semantics of unity), yet distinct from it, on the other hand, because only the former, but not the latter, can be a PERSPECTIZER. In other words, unitization in the group/plurative case is not used just for the sake of being able to count pluralities as groups, but also for the purpose of perspectivizing them as unities. ${ }^{14}$

\section{Semantics and architecture}

One central task for the theory of Number is to establish a set/inventory of empirically motivated syntactico-semantic features that apply compositionally to nominal lattices. The features are made available for natural Number systems, and determine natural classes. I claim that two bivalent features are necessary for establishing these classes, [ \pm atomic] and [ \pm unit]. Only the former notion is usually made use of in a classical mereology. The introduction of the second notion needs new extended mereologies (Meirav 2003; Grimm 2012).

13. The construction (51) is found in Roman (1990), and (52) on the web, <https://www.katarapoet. com>.

14. In Leiss (1994), the role of Gender is seen as supplying a different perspective on multitudes of entities. See also Unterbeck (2000). The idea goes back to Brugman's (1897) attempt to bridge Gender and Number differences in Indo-European. See Fassi Fehri (2018) for detail. 


\subsection{Atomicity}

\subsubsection{Link's model}

In Link's lattice model for Number, the domain $D_{e}$ of entities of type $e$ contains both atoms (singularities) and their sums (pluralities). The model is structured as an atomic join semi-lattice. ${ }^{15}$ The part-of relation of the mereology is $\leq$, and the join operation is $\cup$. If lattices are denotation domains of variables, then Number features are restrictors on these variables (Ojeda 1998-2005; Harbour 2014; Arsenejic 20168 for a restricting view, among others). Thus, given a lattice like (53), 'singular' restricts variables to range over atoms at the lower level, given in (54a), dual to the intermediate level (54b), and plural to the supremum (54c). ${ }^{16}$

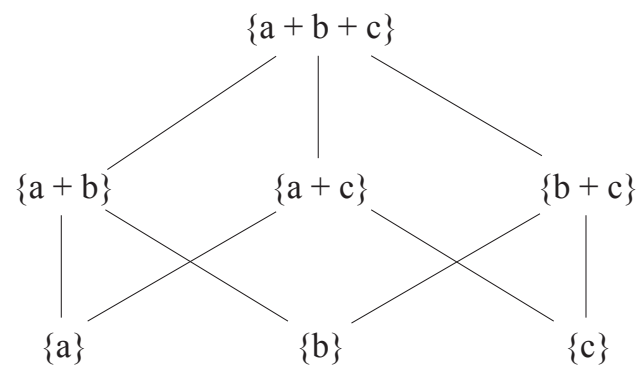

(54) a. $\{a, b, c\}$

b. $\{a, b\},\{a, c\},\{b, c\}$

c. $\{a\},\{b\},\{c\}$

d. $a \cup b=\{a, b\}$

e. $\{a, b\} \leq\{a, b, c\}$

f. $\mathrm{a} \leq\{\mathrm{a}, \mathrm{b}\}$

The relevance of atomicity has been argued by many significant contributions in the semantics of Number, following the lead of Link (1983), including Krifka (1989), Landman (1989), Chierchia (1998), Ojeda (1992, 1998-2005), Rothstein

15. A join semilattice (or upper) is a partially ordered set that has a join for any nonempty finite subset. A meet (or lower) semilattice is a partially ordered set which has a meet (or greatest lower bound) for any nonempty finite subset. A lattice which has both a join and a meet is full or complete; join is represented in Champollion and Krifka (2016) by the symbol $\oplus$, and meet by the symbol $\otimes$. Only join is needed here.

16. As observed by Nouwen (2016), the desired structure is a complete atomic join semilattice. It is complete because the domain of entities is closed under $U$. It is atomic since all atomic parts of sums in the domain are part of the domain. It is a semi-lattice, since it uses only join, and no meet, otherwise it would be a full lattice. In Champollion and Krifka (ibid), a join semi-lattice is defined as a structure for a set $\mathrm{S}$ as a two-place operation on $S$ called join, and symbolized by $\oplus$, such that for each two elements $x, y \in S$, the join $x \oplus y \in S$. 
(2010), to cite few. Its semantico-syntactic properties correlate essentially with shape or size modification, and (direct or indirect) counting, etc., projected as atomP. ${ }^{17}$

\subsubsection{Krifka's countability of atoms and 'natural' units}

In his critique of Chierchia's (1998) explanation of the ungrammaticality of *Dog is barking, as due to the fact that "the meaning of $d o g$ is a property, and properties cannot fill the argument slots of verbal predicates due to a type mismatch", Krifka (2004: 13-14) proposes an alternative analysis in line with Krifka $(1989,1995)$. It states that count nouns have a number argument $\mathrm{n}$, while mass nouns lack such an argument. The latter can be specified by a number word. Their semantic formulas in (55) represent the difference:

(55) a. $d o g=\lambda \mathrm{w} \lambda \mathrm{n} \lambda \mathrm{x}[\mathrm{DOG}(\mathrm{w})(\mathrm{n})(\mathrm{x})],=\mathrm{DOG}$, type $\langle\mathrm{s},\langle\mathrm{n},\langle\mathrm{e}, \mathrm{t}\rangle\rangle\rangle$

b. gold $=\lambda \mathrm{w} \lambda \mathrm{x}[\mathrm{GOLD}(\mathrm{w})(\mathrm{x})],=\mathrm{GOLD}$, type $\langle\mathrm{s},\langle\mathrm{e}, \mathrm{t}\rangle\rangle$

Thus count nouns denote 'extensive measure functions', like gallon or mile, relating a given entity to maximally one number. Moreover, they are additive, in the sense that if $x$ is a sum individual consisting of $n$ dogs, and $y$ is a sum individual consisting of $m$ dogs, and $x$ and $y$ do not overlap, then their sum $(\mathrm{x} \oplus \mathrm{y})$ is a sum individual consisting of $\mathrm{n}+\mathrm{m}$ dogs.

(56) a. If DOG (w)(n)(x) and $\operatorname{DOG}(w)(m)(x)$, then $n=m$.

b. If DOG $(w)(n)(x), \operatorname{DOG}(w)(m)(y)$ and $x, y$ do not overlap, $\neg \exists z[z \leq x \wedge z \leq y])$, then $\operatorname{DOG}(\mathrm{w})(\mathrm{n}+\mathrm{m})(\mathrm{x} \oplus \mathrm{y})$.

The number argument can be filled by number words. The difference in the grammatical number of the noun (in English) is a matter of syntactic agreement with the number word. NPs consisting of count nouns with a specified number argument denote quantized predicates. If the NP seven cats refers to an entity $x$, then it cannot apply to proper parts of $x$, or to individuals that have $x$ as a proper part. This is so because count nouns express measure functions. With mass nouns, quantized predicates can only be built with explicit measure functions, such as gallon. Because classifier languages like Chinese don't have count nouns, they rely only on measure constructions. The classifier is a measure function that may be interpreted either as a measure of the number of atoms of an entity, as in (57a), or as a measure characteristic of the meaning of the head noun, called a 'Natural Unit' (NU) in Krifka (1995), as in (57b):

17. See Fassi Fehri (2003-2004), Svenonius (2008), among others. The attempt to replace 'atom' with other notions such as 'sort'/sortP, 'size' SizeP (de Belder 2008), or 'delimitative' DelP (Zhang 2013) has the disadvantage of lacking any clear or known interfacing semantics. See also Wiltschko (2012) for relevance of [ \pm bounded] and [ \pm animate] features for Blackfoot and other languages, and section 4 below for more detail and discussion. 
(57) san ben shu 'three CL book'
a. $\lambda w \lambda x[\operatorname{ATOM}(w)(3)(x) \wedge \operatorname{BOOK}(w)(x)]$ (measure of number of atoms)
b. $\lambda w \lambda x[[N U(B O O K)](w)(3)(x) \wedge B O O K(w)(x)]$ (measure of head noun, NU)

Thus Krifka's theory of countability makes essential use of the $n$ argument in count nouns, which functions as a measure, and counts atoms, or NU (natural units), which are used to count mass.

\subsubsection{Rothstein's triple atomicity}

Rothstein (2010) follows Chierchia's (1998) account of the semantics of mass nouns under which both the mass and count domains are atomic (see also Barner $\&$ Snedeker 2005 for some psychological evidence, among others). She then postulates three notions of atoms: formal, natural, and semantic. The mass domain is modeled by a Boolean semi-lattice (as in Chierchia, ibid), the denotation of a mass noun is the set of minimal atoms closed under sum, and its minimal elements are thought of as formal atoms. Formal atom is then an atom in the Boolean structure. Semantic atoms are basically singular count nouns, the denotation of which is derived via a measure operation which picks out sets of non-overlapping entities (which count as 'one') by a recoverable unit of measurement. Since the choice of unit of measurement may be context dependent, the denotation of a count noun may be also context dependent. Counting requires access to sets of semantic atoms, hence count (but not mass) nouns can be directly modified by numerals. As for natural atomicity, it is a (gradable) property of predicates of entities which usually come as inherently individuable units. Whether the minimal parts of mass noun denotations is a problem or not has divided the proponents of the non-atomic view (e.g. Link 1983; Landman 1989), and the proponents of the atomic approach (Gillon 1992; Chierchia 1998; Landman 2006). If so, then atomicity in the mass domain is formal atomicity, while atomicity in the count domain is semantic atomicity. The latter is the property of measuring ' 1 ' by some recoverable criterion of unit measurement, or a property of predicates which come in inherently individuable units. The three notions are (independently) defined, as follows (where M-ATOM is a measured or semantic atom; Rothstein, ibid, p. 14):

(58) $\operatorname{M-ATOM}(\mathrm{N})=\lambda x \cdot \mathrm{N}(\mathrm{x}) \wedge \operatorname{MEAS}(\mathrm{x})=<1, \mathrm{U}>$. If $\operatorname{MEAS}(\mathrm{x})=\operatorname{MEAS}(\mathrm{y})=<1, \mathrm{U}>$ and $: \mathrm{x}=\mathrm{y}$, then $\mathrm{x} \prod \mathrm{y}=0$.

(59) Mass noun: $\lambda x . P(x)$

Count noun: $\lambda x . P(x) \wedge \operatorname{MEAS}(x)=<1, \mathrm{U}>$

(60) A predicate is naturally atomic if the function M-ATOM (Nroot) is a constant function.

In Fassi Fehri (2018), I argued that the atom feature is bivalent, with three valuations: (a) [+ atom] for singulars, (b) [- atom] for plurals, and (c) [ \pm atom] for general number. I take the denotation of a singular like $k a l b$ 'dog', or eventually the 
singulative samak-at 'fish-UNIT') to be associated with the bottom line of the lattice. The dual samak-at-aani denotes medial sums, and the ('strong') plural ?asmaak or samak-aat is the supremum of the lattice. More frequently, the plural subsumes the dual, and it extends eventually to all non-atoms and all joins of more than two atoms, other than the supremum. As for general nouns like samak (set noun in Rijkoff's 2002 terms), they denote the complete set in the lattice. Inclusive plurals are equivalent to general nouns. ${ }^{18}$ Moreover, it is essential in this system to make use of the [ \pm unit] feature, which precisely distinguishes more clearly (and in syntactic terms) the singular kalb from the singulative samak-at, but also groups like qatal-at from plurals like qaatil-uu (see (7) and (8) above).

\subsection{Unity}

Various (semantic) theories of groups have been concerned about whether they are singulars or atoms, or plurals or non-atomic (sums or sets), or 'impure' atoms (Link 1984; Landman 1989), i.e. whether they are about 'one', or 'many', or both. The feature [ \pm unit] is supposed to take care of the kind of 'one' which is relevant to the description, as distinct from 'atom'. The idea that the kind of groups discussed involves Gen individuation, in addition to atomic Num, through a convergence mechanism, is the most novel and original in the analysis proposed.

The system adopted in Fassi Fehri (ibid) introduces a unit (or unity) feature, [ \pm unit], which differentiates the various singularities and pluralities along such a specification. Thus the more traditional divisions of singularities and pluralities cross-classify (tentatively) as follows $(\mathrm{Sgv}=$ singulative, $\mathrm{Plv}=$ plurative, $\mathrm{Sg}=$ singular, $\mathrm{K}=$ kind 'collective'):

(61) Atom and Unit classes

\begin{tabular}{|l|l|l|l|}
\cline { 2 - 4 } \multicolumn{1}{c|}{} & +atom & -atom & \pm atom \\
\hline +unit & Sgv & Plv & \\
\hline -unit & & Pl & $\mathrm{K}$ \\
\hline \pm unit & $\mathrm{Sg}$ & & \\
\hline
\end{tabular}

Depending on the viewpoint of the speaker, the plural is 'perspectivized' as a 'unity' (or plurative/collective), or as a non-unity and non-atomic plural (or distributive), as in Leiss's (1994) perspectivization. Likewise, counting singulars does not come as equal, because they are basically either atoms or unities. ${ }^{19}$

18. I concur on this point with Ojeda (1992), Rullmann \& You (2006), and Zabbal (2002-5). See also Sauerland (2003).

19. Another illustrative example of perspective is when non-human plurals are personified and used with a regular plural agreement (masculine or feminine plural), instead of the normal form of non-human plurals (namely the uniform feminine singular). This classification needs more elaboration, to include lexical groups, that are candidates for [ + unit], $[ \pm$ atom], and substance masses, that are presumably unspecified for these features, etc. Further research is certainly needed for elaboration. 


\subsubsection{Meirav's wholes as Unity}

In Meirav's (2003) work on unities, he observes that a neglected dimension in the nature of wholes is the different ways in which parts (irrespective of their individual characters or relations), can compose a whole. In particular, group collective nouns (such as 'group', 'collection', 'class', 'herd', 'flock', etc.) are wholes which have the distinctive characteristic that "their meaning seems to combine the features of being many and being one", with the tendency to treat the whole as "one thing, in spite of the fact that it has many parts, in a way that we do not tend to treat [it as] a set" (p. 33). He then distinguishes a collection, which is identical to the entities of which it is the collection (or sum) of, from a Unity, which is monadic and distinct from the entities which underlie it. "Unities are wholes more loosely determined by their parts than collections or indeed sums" (p. 49).

In general, the notion of an individual involves both (a) an entity being separate from other entities, and (b) an entity which is in some sense one. One sense of 'being one' applies to entities which are prima facie concrete individuals, and can be described as having a 'unity'. A second sense (not be confused the first), is that "a comprising entity possesses unity [...if] the entities it comprises are closely held together". Unity is then used to describe a "type of entities", rather than an entity which is constitutive of being an individual. He then proposes to distinguish unity (in the first sense) from Unity (in the second sense), both being individuals, but of distinct types (ibid: 57-58).

Thus, the theory aims at distinguishing between sums and Unities as two kinds of wholes. Unity, as a comprising entity, is ambiguous between (a) being 'one' (entity), and (b) or being 'many' (not just 'one'). An entity $y$ is one, "if and only if for all $n \geq 2$, and for all $x_{1}, x_{2}, \ldots x$ n (all distinct from one another), $y$ is not identical to $x_{1}, x_{2}, \ldots x$ n (taken together)" (ibid: 68). Sums, as conceived in classical mereology, are non-monadic. The theory of Unities offers an alternative conception of a monadic comprising entity, an entity which may well be a whole (which corresponds to the xs) without being a sum of the xs, a "whole which is not fundamentally a sum" (ibid: 211). Meirav admits that his notion of Unity is still 'vague', although strongly very appealing. It is fortunate that the two distinctions are close enough to be adequately represented in syntax via atomP and unitP.

\subsubsection{Grimm's Individual Scale and Connectedness}

Grimm (2012: 99) observes that Borer's account of nominal structure (or its kins) suffers from its ill-founded empirical basis. First, it is not established that all nominals can be born as mass, neither that count and mass can be made available for all nouns by (universal) grinding or packaging (Pelletier 1979, 2010). Second, it is not the case that nouns are equally mass in all languages from the start. Therefore, not recognizing the constraints on nominal flexibility leads to several missed generalizations.

Grimm (ibid: 102) lists a class of nouns in English that resist grinding flexibility, including group nouns (committee, team, flotilla), abstract shapes (triangle, square, line, point), units of measurement (hour, mile, second, day), nouns of negative space (hole, mouth), or event nouns (trick, act, arrival, blink, smile, run). 
As for resisting packaging, he provides examples of functional aggregates (furniture, change, foliage, mail) and granular aggregates (sand, foliage, barley, dirt). Denying intrinsic countability make a typological prediction, namely that nouns in all languages behave like those in Chinese. But even in Chinese, countability differences are manifested in several ways. Yi (2009) shows that several classifiers in Chinese combine only with what appear to be countable nouns, including the general classifier $g e$. Second, the distributive quantifier geh 'each', as exemplified in (62), is only licit with countable nouns (ibid: 221):

(62) niu (dou) geh you changchu he duanchu cow (all) each have strength and shortcoming 'Each cow has strengths and shortcomings.'

Third, the constrative behaviour of size adjectives (which distinguish countables and non-countables in English, as in Bunt 1985), is also applicable in Chinese. The size adjectives $d a$ 'big' or xiao 'small' are only applicable to countable nouns, and infelicity arises for the Chinese equivalents of 'big water', just as in English. Hence, classifier languages do not lend support to hypothesizing that all nouns are uniformly born as uncountable. Rather, different classes of nouns vis-à-vis countability are detectable.

Grimm not only argues that it is necessary to distinguish objects from masses at an early stage of individuality before counting, but he also argues for the necessity to distinguish between plurals, aggregates, and collectives in languages like Welsh, which have singulatives. In order to account for the two properties of individuation that emerge ('being a whole object' and 'habitually coming together'), he proposes enriching classical mereology with topologically relevant relations (ibid: 159).

Traditional logical tools (set theory and predicate logic) assume that singular entities or individuals are predefined, and because of this, it is difficult to integrate nouns designating, for instance, liquids. They treat individuals in the world which are water in the same fashion as they treat individuals in the world which are dogs. In order to develop a framework in which substances and plural entities are given equal standing as singular entities, the most widely adopted view is to model plural and non-countable terms using mereology, the theory of parthood, a standard set by Quine (1960). The lexical core of a mereological theory is provided by a treatment of the 'part-of' relationship (which is reflexive, antisymmetric, and transitive).

The extensions proposed by Grimm amount first to represent the distinction between objects and substances. It is a foundational distinction in countability between entities viewed as coming in 'minimal units' as opposed to those not coming as such (contrary to Chierchia's 1998 view). Second, there is an important distinction between plurals and aggregates (i.e. sums which correspond to plural individuals, 'boys', and sums which correspond to aggregates, like 'foliage', 'sand', 'furniture', etc.). Given the important role played by aggregates in grammatical number systems, any account should be able to distinguish the two types of entities, in view of primary motivations for adding topological relations. This is achieved 
through recognizing self-connected entities, that is individuals which cannot be divided into two separate parts. ${ }^{20}$

Grammatical number categorization then reflects different degrees (or types) of individuation associated with nominal descriptions. Countability is no longer a binary distinction, although some languages may only have two primary categories (countable and non-countable); it is rather a scalar phenomenon in general. Second, a noun's countability status is not purely a grammatical fact, but it is based on individuation properties associated with distinct topological properties of different countability types.

The examination of languages with a collective/singulative class provides a different perspective on what underlies countability, compared for instance to English. Languages such as Welsh, Turkana, Maltese, Dagaare, recognize aggregates as qualitatively distinct from singular entities or non-countable nouns, and this variation should be constrained by the scale of individuation. If two nouns describe the same set of objects, e.g. leaves and foliage, this does not indicate arbitrariness of countability classification, but rather different perspectives of the entity type (p. 159). Whole objects may be characterized in terms of maximally strongly self-connected individuals, and the notion of coming together through various connectedness relations. The shift in perspective is from classical mereology to a mereo-topological view. Many languages make distinctions which are related, but not identical, to collective singulative classes. Italian disposes of an irregular plural $-a$ which applies to a lexically restricted set of nouns, e.g. braccia 'arms', contrasting with the regularly inflected plural bracci which designates 'arms of objects' (Acquaviva 2008, or more recently Manzini \& Savoia 2016, and Acquaviva 2017; see also below tree (95)). In the same vein, Fassi Fehri (2003-4, 2012) denies a uniform mass base for all nouns from the start, distinguishing various types of individuality. It is implemented via atomic and unit features here, as well as in Fassi Fehri (2018), projecting atomP and unitP. ${ }^{21}$

\section{Crosslinguistic variation}

Forms of group classification involving Gender, which involve gender/number convergence are found in various languages in various forms. Indeed, instantiations of this sort occur in Slavic) Serbo-Croatian or Polish) in numeral contexts, or group classification in Burmese or Chinese classifier languages. Yet 'collectivization'

20. Note that these stricto sensu aggregates should not be confused with what I call kind-collectives like waraq 'leaves', or naml 'ants', which provide singulative units in Arabic or Welsh collective-singulative languages, although the distinction is often blurred in the literature.

21. Seifart $(2009,2010)$ observes that the better-known devices of unitization, numeral classifiers and singulatives, ... operate on a noun that does not make unambiguous reference to single, countable referent in its basic form, transforming it into an expression that does make unambiguous reference to a single, countable referent. He uses the term 'unitization' as a cover term for individuation and singularization, i.e. to refer to the formation of a singular object noun from any other noun type (including collective or set nouns). But I depart from this notion of unitization, the unitizer and the singular (atomizer) being two different processes. 
found in Italian is clearly a distinct process, a form of aggregate-collective rather than group-collective.

\subsection{Serbo-Croatian 'collective'}

Consider first Serbo-Croatian (= SC). It has been argued e.g. by Arsenijević (20162018) that "neutral gender in SC displays a number of surprising properties, [... most of which] occur only when plural reference is involved (established, next to plurals, also by collective nouns and by conjoined singulars)". Of the four classes of derived collectives, only one is both productive and constrained to nominal bases, the class of collective nouns in -ad, formed from only neuter nouns, as in (63). Others, like the collective with $-a$ in (64), are not productive or regular: ${ }^{22}$

(63) pras-e piglet-NOM.F.SG; $\rightarrow$ 'piglet'; pras-ad piglet-COLL.NOM.F.SG 'piglets (collective)'

(64) vlastel-in aristocrat-SG.NOM.M.SG 'aristocrat'; $\rightarrow$ vlastel-a aristocrat-COLL. NOM.F.SG 'aristocracy'

According to Arsenijević (ibid), this morphologically marked collective can be viewed as a 'coercing classifier', shifting the unit from 'atom' to 'group'. The suffix which attaches to the count nominal stem counts units which obviate the lexically specified atomicity, through a 'paucal' classifier. It shifts the unit of partition (or counting) from an atom to a (paucal, 2-4 atomic) group. It only attaches to atomic bases, because the paucal classifier needs to apply to an atomic structure. As described, those collectives are almost equivalent to plurals, but the difference is that plurals also denote (sums of) singleton atomic parts, while collectives bottom at the level of paucal groups. Such a description fits well with taking these 'paucal' collectives as pluratives instantiating gender/number convergence. It is worth pointing out that the restriction on Serbian derived collectives to count bases entails that mass nouns are not atomic in any significantly relevant sense. This speaks against both Chierchia's view of masses as equally atomic, as well as Rothstein's formal atomic analysis of masses. Indeed, if the Serbian suffix does require a base denoting over a domain that has a bottom atomic level, regardless of how stable or uniform these atoms are, and mass nouns are excluded, then the denotation domain of mass nouns is not relevant to atomicity.

22. Other collectives that I do not take into account include collectives like the following:

(i) gran-je

branch-COLL.NOM.F.SG

'Branches (collective)'

(ii) gran-a

branch- NOM.F.SG

'A branch' 
In Arsenijević's view, there is an 'overriding' process taking place in these sorts of pluratives or groups. As an illustration, he provides the Chinese contrast brought up originally by Krifka $(1995,9)$, where the selection restriction of the noun for a default classifier has been overridden by the classifiers gun ' $\mathrm{Cl}$.herd' and zhong 'Cl.species' in (65):

(65) san qun/zhong xiong

three $\mathrm{Cl}_{\text {herd }} / \mathrm{Cl}_{\text {species }}$ bear

'Three sleuths of bears / three bears (species)'

More motivation for convergence (in my terms) is at stake in (66), originally brought up by Wechsler and Zlatić (2003); to illustrate a combination of plural agreement (on the finite auxiliary or copula) and the ending $-a$ (ambiguous between NPL and FSG), on the participle or predicative adjective, respectively: ${ }^{23}$

(66) braća su spaval-a

brother.COLL.NOM.F.SG Aux.PL slept-NOM.F.SG/NOM.PL

'(The) brothers slept / were sleeping.'

Arsenijević (ibid) correctly argues that the collective meaning results from a complex operation involving a plural atomization plus a refinement/restriction operation which narrows the denotation of the collective to (some) sums only (excluding atoms), an analysis that comes close to my account of pluratives (or syntactic groups). What is unaccounted for, however, is the unity of the 'collective'. The unity property (and other details) aside, the analysis highlights the complexity of the group collective formation, and it is compatible with thinking of the collective as a convergence of Number and Gender (or convergence of atomicity and unity), the manifestation of which is instantiated by the 'hybrid' agreement behaviour of the collective 'plurative' seen above (as distinct from the other collectives). ${ }^{24}$

\subsection{Polish 'gendered' numerals}

Wagiel (2018) argues that Gender in Slavic is also a classifier, or a mode of quantification, typically required in cardinal constructions, to allow the numeral to operate modification. In the contrasts given below, the bare/unmarked cardinal is used to

23. Wechsler \& Zlatić (ibid) include an index feature specification (NP1) to account for this convergence (in addition to their concord features, FSg, and semantic features, MPl), but Arsenijević (ibid) criticizes the introduction of index features as a third feature type (see more references there for motivation of this critique).

24. A reviewer asks the question whether Serbian collectives which only denote small cohesive groups can be predicted not to be used to refer generically (like English bare plurals), and at the same time whether the Arabic plurative can admit a generic/kind reading. As far as I can tell, the prediction appears to be borne out in Serbian, as well as for the Arabic plurative, which is not generic/kind referring, but rather maximal and definite. 
name numbers in (67a) ( $n$-terms or abstract mathematical objects), whereas the marked cardinal in (67b) is infelicitous ( $v$ for 'virile', and nv for 'non-virile'):

(67) a. jeden, dwa, trzy, cztery, pięć, ... one.NV two.NV three.NV four.NV five.NV 'one, two, three, four, five...'

b. \#jeden, dwaj, trzej, czterej, pięciu, one.v two.v three. $\mathrm{V}$ four. $\mathrm{V}$ five. $\mathrm{V}$

In (68a), the unmarked cardinal counts 'non-virile' objects, whereas the marked 'virile' gender in (68b) counts 'virile' objects:

(68) a. Tych pięć dziewczyn przyszło

these five.NV girls.NV came

'These five girls came.'

b. Tych pięciu chłopców przyszło

these five.v boys.v came

'These five boys came.'

Wagiel then proposes that this gender is a (highly grammaticalized) numeral classifier, enabling modification (more like intersective adjectives). The analysis builds on the idea that numeral roots are category-free, and that cardinals have nominal-like properties, being used as modifiers, predicates, or names of numbers. A gender value is always associated with the numeral head which forms the cardinal. The derivation of the marked cardinal pięciu 'five' differs from its unmarked counterpart. The numeral root in the tree is a singular term, i.e. nothing more than an expression of type $n$. The numeral head can not only assign the virile gender value, but it introduces the classifier meaning, which shifts the number to the cardinal property corresponding to that number. Hence the difference in interpretation in these constructions is that the virile numeral head introduces classifier semantics. The simple mechanism proposed explains the non-trivial semantic contrast between marked and unmarked cardinals by associating grammatical gender with classifier semantics. Similar contrasts are brought up from Bulgarian and Slovak, in addition to Arabic and more other languages (ibid: 436-437). The analysis is in lines with Fassi Fehri's (2018) analysis of Arabic gendered numerals, as well as Arsenijević's (2016-2018) analysis of SC collectives. It also builds on Sudo's (2016) evidence that Japanese numerals are exclusively singular terms, which cannot function as predicates on their own (see section 4 for discussion). It is then proposed that the semantic function of classifiers is to turn such singular terms into modifiers/predicates.

\subsection{Burmese collective numeral classifiers}

In the same vein, Rijkhoff (2002) observes that Burmese has sortal singular and collective classifiers which occur obligatorily with numerals, to count two kinds 
of discrete entities, singulatives and collectives. According to the author, these (nominal 'aspect') markers specify the 'kind of set entity' which is referred to, a singleton set, or a collective set, as in the following contructions (taken from Okell 1969: 209-211);

(69) hkweì hnă kauñ

dog two CL

'Two dogs'

(70) pyà hnă ouñ

bee two swarm

'Two swarms of bees'

(71) pàñ hnă sì

flower two bunch

'Two bunches of flowers'

This 'analytic' distinction of the two numeral classifiers as singular and collective is parallel to that found in Chinese, and to the subtle gender distinctions in singular/collective numeral constructions as already analysed in the literature (see Fassi Fehri 2018, for detail and references).

\subsection{Chinese group collective -men}

Fassi Fehri \& Vinet (2004: 12-14) observe that Plurals/Numbers are found in Chinese, although they usually carry additional specific information, which then limits the range of their use. Among such information is 'definiteness', which has led some authors to analyse plural forms like -men as ending in D in syntactic structure, although the latter is chiefly analysed as a plural Num form (cf. e.g. Li, 1999). Second, there is a 'collective' interpretation which has been claimed to be characteristic of the suffix -men, and which has led to a dispute on whether the latter must be analysed as a 'collective' group marker (see Iljić 1994, 2001; Cheng \& Sybesma 1999, among others), or just a 'plural' (Li; ibid, among others). Note that -men occurs normally on pronominal forms and animate or human nouns, to express a form of plurality, as illustrated in (72). The combination in (73) is not felicitous because it is used with a non-human noun (cf. Iljić, ibid):

(72) a. wǒ-men

$1 \mathrm{~s}-\mathrm{MEN}$

'We/us'

b. lăoshī-men

professor-MEN

'Professors' 

(73) * y̌̌zi-men
chair-MEN
'Chairs'

The marker $-x i \bar{e}$, on the other hand, identifies an indefinite plurality, in e.g. $(y \bar{\imath}) x i \bar{e}$ in (74a). It is not a classifier, since it can co-occur with other (prenominal) classifiers, as in (74b), where it is suffixed to a demonstrative, and it contributes plural quantity:

(74) a. ȳ $x i \bar{e}$ shū one XIE book

'A few books'

b. zhè-xiē kŭn shū

DEM-XIE CL book

'Those piles of books'

It is observed that more productively, group plurals appear to be formed in syntax through a movement process, through which $\mathrm{N}$ first moves to the left of the $\mathrm{Cl}$, then the $\mathrm{N}-\mathrm{Cl}$ sequence moves higher to the Num phrase. The examples in (75) and (76) illustrate the contrast between singular/individual and plural/group readings of the two DPs:

(75) yǒu sān qún rén zài shuōhuà

have three CL people at speak

'Three groups of people are speaking'.

(76) rén qùn zài shuōhuà

people CL at speak

'People are speaking'.

Returning to the properties of the suffix, it is important to note that although -men implies plurality, as is clear with pronouns in (72a), it merely indicates that the members of a particular group should be considered together as a unit, and it "marks a subjective location: several individuals are grouped together relative to the speaker or some other subjective origin" (as Iljić 1994: 91 put it). In this case, it is best treated as group collective, basically referring to a whole. However, its grouping function does not obviate the fact that it applies to pluralities, rather than singularities, thus exhibiting a 'hybrid' behaviour. The specific collective nature of -men (as distinct from that of a 'regular' plural) is further corroborated by the fact that it suffixes to proper nouns, as in (77), from Iljić (1994):

(77) Xiăo Qiángmen

Xiao Qiang-MEN

'Xiao Qiang's group' 
The suffix then serves to identify a group relative to a certain person. It is said in the literature that it can be read as a sort of 'associative plural'.

Moreover, as observed by Zhang (2013: 66), quoting Hsieh (2008), -men may occur with a numeral, if the classifier is a collective CL, as shown in (78), compared to the infelicitous (79), confirming that it can be counted like groups (modulo the appropriate context):

(78) na san qun xuesheng-men

dem three CL student-MEN

'Those three groups of students'

(79) san ge laoshi (*-men)

three CL teacher $(*$-MEN)

'Three teachers'

If so, then the -men phrase once interpreted as a group (as in Fassi Fehri \& Vinet, ibid) is better analysed as UnitP over NumP, as in the case of Arabic pluratives embedding broken or sound plurals. ${ }^{25}$

\section{Further motivation and variation}

The complex convergent analysis of pluratives proposed (and eventually that of singulatives) can be contrasted with competing simple or non-converging analyses. In morphosyntax, the latter analyses would take the plurative as simply a plural (or Number), or as solely a Gender (or classifier). In a parallel fashion, the semantics of group collectives would take them as simply having a singular (or atomic) reference, or simply having plural (set or sum) reference. Alternatively, groups of the sort discussed are a third complex entity, which makes 'many' (or non-atomic sums) as 'one' (or a Unity), and projects two distinct features as atomP and UnitP. The inadequacy of simple analyses is further discussed in this section, pointing to more 'hybrid' properties, and more motivation for the convergent approach. Core notions are critically re-examined, and more cross-linguistic variation investigated in the light of convergence.

25. This type of collective reading on proper nouns is far from unique. It is found in other languages, namely Tok Pisin, and Berbice Dutch. See the details and references in Fassi Fehri \& Vinet (2004: 12-14). See also Iljić (ibid) for more other subtle properties of -men, which make this analysis tentative, but presumably incomplete. A reviewer correctly pointed that (78) and (79) are not minimal pairs, since only the former carries a definite demonstrative, and "it could be that the group interpretation of the set restricted by the numeral arises because of both the choice of classifier and the presence of the demonstrative". While this option is possible, it would be more elegant to keep separate the contribution of the group classifier (to group or collective meaning), and the contribution of the determiner (to 'maximality' or notions of similar sort), as argued for in Fassi Fehri (2018) for Arabic. 


\subsection{Convergence}

The notion of convergence conveys the idea of a syntactic process, by which union of categories or features converge in a derivation to form a new unified category/ entity, which has a full interpretation (FI). In Chomky (1995: 219-220), "a derivation converges at one of the interface levels if it yields a representation satisfying FI at this level, and converges if it converges at both interface levels, PF and LF; otherwise it crashes". The features on the controller of both number and gender converge to form the category or feature(s) of group. Group is precisely convergence/'coalescence' of both Gender and Num in a typical way, namely that Gen/individuation is over (or higher) than Num in this case, while in a geometry of features like that of Harley and Ritter (2002) it should not be. In a sense also, two 'numbers' converge on the plurative, one is the upper number 'one', and the other is the lower number 'many' (or sum). The group is at the upper level 'one' (or unity), and at the lower level 'many' (a multitude or sum). Without convergence of these two 'numbers', or these two distinct individuations, the syntax and semantics of a group cannot be met. ${ }^{26}$

It is to be noted that the notion of convergence used here, which is syntacticosemantic, along the lines of Chomsky (1995), is different from that of the convergence/syncretism discussed by Corbett (1991: 155), or Kramer (2018: 161), a form of neutralisation (or morphonological impoverishment). For example, the French plural definite determiner les is taken to be a case of such an impoverishment, because it is genderless, compared to the feminine singular $l a$, or the masculine singular le. It is a distinct plural form used for nouns of both genders, which represents a pattern of 'convergent-to-plural Gender' impoverishment. A similar pattern is found in Coptic, where [+PL], [ Fem] inputs [+PL] (only). Contrastively, a 'convergent-to-Gender'pattern is found in Maay (a Cushitic language), where the definite determiner plural form (and determiner agreement) is syncretic with the masculine singular form (feminine: - $t i$; masculine: $-k i$; plural: $-k i$ ). In other words, $[ \pm$ Fem] singulars output (only) $[-$ Fem] in the plural (without Number specification; Kramer, ibid: 168, rule (7)). ${ }^{27}$

Convergence as conceived here is (essentially) not a morphonological (or syncretic) process. It rather concerns syntactic derivations and semantic compositions, as explained and motivated above. Intuitively, the sets of features of the distinct $\mathrm{A}$ and $\mathrm{B}$ categories converge at $\mathrm{C}$ iff features of $\mathrm{A}$ and features of $\mathrm{B}$ are interpreted at C. Converging categories imply converging features. As explained earlier, pluratives manifest a dual behaviour: (a) one like a unitizer (or Gender), and (b) one

26. A reviewer appealingly pointed out that the notion of convergence of features proposed is more insightful and precise, given that two features converge when they coalesce to form a third complex feature. But it does not sit so well with convergence as a (stative) property akin to well-formedness, whereby a converging derivation is just one where the output representations are fully interpreted. While I agree that the two notions described in their strict senses are somehow distinct, more like when we talk about convergence as syncretism, I keep open the option of interpreting these various senses as different routes to convergence as full interpretation.

27. See also Gray \& Gregor (2019) for an application of the latter pattern of convergence to the Papuan language Yelmek. 
like a plural (or Num). The plurative can occur on the controller and/or the controllee (the probe-goal of Agree), or it occurs only on the controllee. That is the case when plurals are 'coerced' to be plurative, and hence function as groups. As seen in (36) above, there are two human individuator morphemes competing for a (hypothetical) collective base. One is the human singulative - ii, and the other is the human group individuator -at. With numerals, counting does not target the same individual. It can count the single individual - $i i$, or the group individual $-a t$, as in the following contrast:

(80) xams-at-u sunn-iyy-iina

five-FEM-NOM sunn-UNIT sgv $_{\text {-PL.GEN }}$

'Five (individual) sunnis'

(81) xams-u sunn-aat-in

five-NOM sunn-UNIT plv -PL-GEN

'Five groups of sunnis'

The group reading in (81), as well as the form of agreement there (as an 'inverse gender' agreement on the numeral, depending on the gender of the counted nominal, and as plural on the nominal agreeing with the low numeral) not only show that both the singulative and the plurative can be counted as different units, but also that there are two distinct unitizers competing for the same (general/ collective) base to shape a unit (although distinct). ${ }^{28}$

\subsubsection{Plurative}

The term plurative is used to distinguish the gendered suffixed form (uniformly feminine) from other forms of plurals, when the common plural is 'sound' or 'broken', as discussed in section 1. In the latter case, gender is also variable (with differences between sound and broken).The reason that I resort to this terminology (otherwise justified in Fassi Fehri 2016), rather than just talk about groups, is that the latter have no unified morpho-syntax, and they are often thought to be semantically polysemous. I do not use the term collective either due to its vagueness. Furthermore, collectives often designate general noun phrases that can denote singularities as well as pluralities, but groups are not singularities, although they also have ambiguous syntax. The term plurative is most suitable to mirror the fact that the two morphosyntactic processes are parallel, one building a specific singular, and the other a specific plural.

Plurative is more than a classifier whose semantic function is to specify a unit for counting (or operate a partition or division, which it does not do). It is rather perspectiving a unification of the plurality as a whole sum (rather than a collection of separate objects). When broken or sound plural nominals are used as plurative,

28. See Fassi Fehri (2018; Ch. 3) for detail of numeral agreement in low numerals. Note that (81) can have a taxonomic reading, whereby the counted units are the 'kinds' of groups, rather than the groups themselves. 
it is reasonable to think that a (hidden) group classifier shifts the interpretation of the plural from an undifferentiated sum to a unity. Obviously, the plurative DP is not semantically singular, or atomic. Its plurality is established through various tests of plural reference, reciprocity, group event predication, etc. (see Fassi Fehri 2012: Ch. 5, and Fassi Fehri 2018: Ch. 5, for detail).

Landman's group forming operator $\uparrow$ 'uppermaps' possibly plural individuals to 'impure atoms'. He assumes that collective interpretations yield distinct entities called groups, which are related to their 'underlying sums' via a group forming operator $\uparrow$. While sums have proper parts, impure atoms, in his view, are atoms derived from sums via the group operator, and have no proper parts. Thus, in (82), the noun phrase Susie and Marie is ambiguous between Susie-and-Marie -as-a-sum, represented in (82a), and Susie-and-Marie-as-a-group, as in (82b):

(82) a. $\llbracket$ Susie and Marie $\rrbracket=m \oplus p$

b. $\llbracket$ Susie and Marie $\rrbracket=\uparrow(m \oplus \mathrm{p})$

Morphological nominal pluratives are plurals overtly marked with the feminine singular (group classifier), which may or may not be internally marked overtly as plurals (see baraaber-at 'berbers as group', karaadil-at 'cardinals as group', etc.). Syntactic pluratives exhibit this behaviour only on the predicate (verb or adjective), which is marked as (group) feminine (singular). Num-Gen convergence describes this complex situation in which the controller and/or the controllee manifests Gender, and in fact no (visible grammatical) Number. In a syntactic plurative configuration, both the DP and the predicate have to be interpreted as a unity of a sum of individuals, performing a unified (or 'collective') action. In a sense, a plurative enables us to see a DP as denoting at the same time the entity described as 'many', or more than one ( $>1)$, or as 'one' $(=1)$.

To represent this convergence of number and classification, and using Landman's formalism for groups (also well-known LFG grammar representations), it is possible to represent the individuation $(\mathrm{Gen} / \mathrm{Cl})$ and the Num values of pluratives/groups as follows:

\section{(83) Plurative}

Gen $=\uparrow ; \mathrm{n}=1 ;$ Num $=\downarrow ; \mathrm{n}=>1$

The semantics of the entity formed can be seen as a superposition of two lattices, one over the other, adequately represented by two hierarchically ordered features/categories, atomP and unitP in syntax, in the right order ${ }^{29}$ It is basically the information associated with groups, which makes them ambiguous between the

29. In fact, (83) can be simplified as (i)

(i) Group: $\uparrow=1 \& \downarrow=>1$

The option of a superposed 'double lattice' is already entertained in Link (1984) and Landman (1989). 
normal plural reading and the unity reading, reflected in plural/singular agreement alternation. The duality of number/individuation in groups is associating number of the parts and number of the whole. Only one of them can surface on a predicate (the upper number, or the lower number), i.e. a verbal predicate. In the latter case, only the upper Number (or the number of the mother node) in the DP structure is reflected in the agreement configuration with the predicate, together with its Gender (or classification).

Other theories of groups such as Ojeda $(1992,2005)$ conceive of groups as restrictions of pluralities (see also Arsenijević 2016-8). Ojeda takes group to be an 'endomorphic image' of a subset of the universe of discourse. Arsenijević restricts its denotation to the part of the join semi-lattice without atoms. In all these 'atomistic' theories of groups, it is not clear, for example, how the dual of group or the plural of group can be included in the atomic join semi-lattice of Link's kind (which includes singular, dual, and plural individuals, but see fn. 21). Moreover, describing groups as impure atoms or restrictions on sets of atoms (inside the atomic lattice) is different from conceiving them as entities of different kind, namely unities. Then the morpho-syntactic mechanism of convergence may operate to fuse atomic and unify projections in various configurations, as illustrated in (34), (38), or (41) above. As such, the view of (syntactic) groups I am arguing for is qualitatively different from most other competive counterparts, which are widespread in the literature.

The plurative as a syntactic unity or group classifier is distinct from lexical groups. It is necessarily feminine singular, morphologically marked compared to other groups (which are not necessarily feminine). It is syntactically distinct from lexical groups because it triggers a syntactic agreement which is feminine (singular), while other groups do not. It can be formed over other plurals (broken or sound), or Number, but cannot do so over other groups. I assume that processes of unitization (or reunitization), or atomization (or re-atomization) contribute to building Num or Nmr structures. I concur with Bale \& Coon (2014) and Bale, Coon \& López (2019) that partitioning and measuring structures may or may not be relevant for the sake of Nmr or Num.

The plurative is a morphosyntactic process by which you can typically form a syntactic group. In this narrow sense, the plurative informs us about properties of syntactic groups, as distinct from those of plurals. Moreover, this kind of groups have distinct behaviours from those of lexical groups. The most salient property of pluratives then is that they behave like a unitizer phrase (although they can be shown to be semantically plural). This property is not exclusively due to morphology, witness the fact that regular sound and broken plurals can also be used in (or as) unitizer phrases, as we have seen with constructions (49)-(50) and (51)-(52) above, respectively. The (unit) morphology is then found solely on the predicate. Once a plurative configuration is obtained by matching the subject and the predicate feature, the morphosyntax of plurativity becomes clearly distinct from that of sound plural or broken plural constructions (in addition to non-human plural constructions). Conversely, a plurative DP can be used as a normal plural with no unitizing morphology on the predicate, as in (9) above. It is important to point out, however, that Arabic plurative DPs are not truly ambiguous, even though they can 
govern either singular or plural agreement, because both manifestations are facets of the semantic content of the plurative. When individual members of the group are accessible as a (distributive) plurality in this construction, but not in other group expressing constructions (in English, we don't have *Jack and Jill as a group met, yet we have (9) and (16) in Arabic), the answer to the puzzle seems to be that pluratives are syntactic complexes, and either the lower Num or the higher Unit can govern agreement. ${ }^{30}$

If the function of Number is to quantify over the number of entities, and the function of $\mathrm{Cl}$ is to create the entity that Number is supposed to quantify over, then Number presupposes classification or individuation, and it is represented higher than the $\mathrm{Cl}$ or Gen, for this reason. It is a quantifier in this case, although (plural) number can also be an individuator of the lower level (as argued for in Borer 2005). Number (normally) presupposes classification, but in the case of the plurative, it seems that the classifier (or Gender) is presupposing Number, and hence it is higher than Number. It can select an already plural base of individuals, to create a unity. If the plurative were a refining process (more like the singulative with respect to the collective, which selects the lower bottom of the lattice; Ojeda 1992), then it would select the upper part (Ojeda 2005; Arsenijević 2016-8, among others), and in practice, the group would be a restrictor on the interpretation of plurals. Plural can be collective or distributive, but Group is only collective (in the core case). But the plurative is not just an atomic restrictor; it is the convergence of number and gender, being somehow both 'quantifying' (the parts) but also 'qualifying' the comprising entity (the whole). Hence, it is neither just a true singleton atom, nor a set of atoms. Even if its atomicity is taken to be complex (with two layers, as in the case of 'impure' atoms), it is not enough to describe its behaviour, as compared to the behaviour of other collectives that are not unities. ${ }^{31}$

\subsubsection{Singulative}

The term singulative is used to distinguish a gender marked fixed form (feminine in Arabic) from the more common singular form (and category), where the singular is the unmarked form, compared to the plural. In the latter case, gender is variable (e.g. can be masculine or feminine). But the singulative is gender marked, and its feminine is invariable.

30. Thanks to a reviewer for helping me clarify the importance of this characterization of the process.

31. Haspelmath \& Karjus (2017) have also an innovative use of plurative and singulative terms as key (comparative) formal concepts (for the purpose of investigating frequency), whereby basic/plurative pairs and singulative/basic pairs are identified, depending on frequent marking. "A basic/plurative pair is a pair of related noun forms where one member is an unmarked (basic) uniplex noun (e.g., day), while the other member is a marked multiplex noun (e.g., day-s). Since this situation is extremely common in the world's languages, the great majority of "plural" forms are actually pluratives in this sense". On the other hand, a singulative/basic pair is "a pair of noun forms where one member is a marked uniplex nominal (e.g., Welsh moron-en 'carrot'), while the other member is an unmarked multiplex nominal (e.g., Welsh moron 'carrots'). Since this situation is quite rare, few "singulars" are singulatives." (pp. 1216-7). This terminological use is not welcome, however, given that it blurs the typological variation of individuation we are interested in, as well as the empirical and theoretical issues associated with. 
It is common to treat singulatives as atoms, just like other singulars (which are also treated as atoms). However, as we saw earlier with Krifka's view, being an atom calls for a measure as ' 1 ' (or being a 'natural' atom as Rothstein defines it). Whatever view is adopted, there is no way a singulative can be treated as simply a 'natural' singular. If singulatives are distinct from singulars, it is more plausible to see a singulative semantically and syntactically as a convergence of two forms of individuations. Its base is a partially individuated or (weakly) atomized (starting as a kind 'collective'), then unitization is brought out by the classifier, 'refining' the denotation of its 'collective' base to only the lower part of the semi-lattice, that is, to atoms. Singulative is then a refining or restricting process (Ojeda 1992, 2005; Grimm 2012), which inputs a kind (or general) individual collective, and outputs only the set of single atoms, or more precisely units. In Ojeda (2005), modification in terms of size and shape is mentioned as a known property of count nouns (and not of mass). Svenonius (2008) accounts for the incompatibility of 'sortal' adjectives and mass nouns by merging the former in the Spec of SortP, the locus of count nominals. Along similar lines, Zhang (2013) proposes that two features ('numerability' and 'delimitability'), rather than just one (as in Borer's DivP), are both relevant to countability of nominals. ${ }^{32}$ This is clearly in continuation of my old 'atom' and 'singulative' features (Fassi Fehri 2003-4), or my more refined current atomP and UnitP (see also Fassi Fehri 2018). If so, the singulative is not a divider in any sense; it does not project as DivP (the coarse notion of Borer's, ibid), contra Mathieu (2012); see the appealing discussion of distinct singulatives in Acquaviva (2015). Only when two features are involved, can we then explain why singulatives are most frequently derived from kind collectives (ism jins 'noun of species'), rather than from substance mass, object mass (or mass collectives), or group collectives (and acknowledged as such since Greenberg 1972, back to the middle age Arabic tradition; see e.g. Astarabaadii, 12th c.). Masses are not naturally atomic, and hence do not provide a natural base for deriving singulatives, which are both atoms and unities, according to (59). A 'packaging' operation is then needed to create units from masses. Groups are already unities, and no unitization can operate on them (unless vacuous), etc.

Earlier in the article, I explained that in addition to singular and plural individuals, there is thus a 'third entity', a third complex individual, which I called the 'plurative', as represented in (83). In parallel, the singulative can be thought of as a 'fourth entity', which is also complex in its individuation; it is represented in (84):

(84) Singulative

$\downarrow=\geq 1 \& \uparrow=1$

32. The features project as UnitP (the unit word being the head), and DelP (which hosts delimitative adjectives), in addition to NumP (or \#P), which represents Number markers (Ritter 1991, 1995, and Borer, ibid, respectively). It is claimed that the main semantic function of classifiers in numeral expressions is to represent a unit for counting (rather than make a semantic classification); it is more than dividing (Zhang, ibid, 111-114). 
What singulative and plurative (in its narrow sense) have in common is that both exhibit a Gender/Number convergence, in the sense that the affix is there for both categories or features.

It is important to note that the qualification of singulatives proposed predicts that they are impossible as kind-generic denoting expressions. As far as composition with kind-level predicates is concerned, the prediction is borne out, witness the contrasts in grammaticality in (85) and (86) between the kind and the singulative.
a. n-naḥl-u qad y-anqarị̂-u fii ș-șiin-i (*Caadat-an) the-bee-NOM may 3-become.extinct-INDIC in the-China-GEN 'Bees may become extinct in China'.
b. * n-nahl-at-u qad t-anqarị̣-u fii ṣ-șiin-i the-bee-UNIT-NOM may FEM-become.extinct-INDIC in the-China-GEN

As far as 'characterizing' genericity is concerned, both the kind and the unit are possible (see Krifka 1995 and references there for the properties of the two types of generics):
a. n-naḥl-u y-alsą-u
the-bee-NOM 3-bite-INDIC
Bees bite (usually).
b. n-naḥl-at-u t-alsą-u mitl-a z-zunbuur-i (Gaadat-an) the-bee-UNIT-NOM F-bite-INDIC like-ACC the-wasp-GEN (usually-ACCC) The bee bites like the wasp (usually).

One differentiating test between the two types of generics is the (in)compatibility with overt adverb of quantification. Such modification is impossible with the kind predication in (85), while it is allowed with the characterizing generic in (86). While the examination of the various patterns of genericity and their distributions (with respect to plurals, kinds, singulars, singulatives, or plurals of singulatives) is far beyond the scope of this article, it is important to note that individuations and/ or numbers clearly behave distinctively in a significant number of contexts, and typically in kind-generic vs. characterizing generic contexts. ${ }^{33}$

\subsection{Collectives of various types}

As amply noted in the literature, there are many uses of the term 'collective', which apply to distinct individuation/number entities, or collective types, and make the term almost useless, unless it is given a precise content (Gil 1996: 66-70; Corbett 2000: 117-120, among others). The important distinction I have focused on here is that between kind (individual) collectives (basically equivalent to Corbett's 'general nouns'), from which singulatives are normally derived, and group collectives

33. Thanks to a reviewer for bringing up the interest of exploring such contrasts. See also fn. 10 above. 
(or simply groups). In the latter types, a distinction can be made between 'lexical' groups (like Pusrat 'family', fariiq 'team') and 'syntactic' groups (like katab-at 'writers', sadan-at 'guardians', i.e. my 'plurative'). Arabic traditional grammarians also distinguish ism jam S 'noun of plurality', which is equivalent to group collective, and ism jins 'noun of species', which is equivalent to kind collective (or general noun), in addition to a long list of plurals; see Fassi Fehri (2003-4, 2012) for these various types of Arabic collectives, and Wiese (2012) as well as Mihatsch (2015) for the importance of even further qualifications and distinctions in other languages. All these types specify a way of viewing members of a group or a sum, or the comprising entity, as construed together, as a unit (with various degrees of visibility of members, or minimal parts), while distributives indicate that members must be considered visible and separate. In Salish, the collective morpheme usually refers to "a group of items considered together rather than a number of items considered individually. Translations usually are in the form of phrases such as "a bunch of ...", or "lots of ...", which express a cohesion of a group, while distributives are often used for "entities dispersed over space, nominal collectives typically refer to entities that are spatially contiguous" (Corbett ibid: 119).

\subsection{Collective as form-meaning pairing}

De Vries (2019, to appear) comes close to our idea of convergence, when she adopts the view that the collective is a property of form-meaning pairing, "which has a singular form, but plural reference", behaving like singulars in some respects, but like plurals in others. It is neither just a particular morphosyntactic form or feature of Number, in addition to singular and plural, as it appears to be the case in languages like Welsh, Maltese, and Arabic, nor just a semantic property predicated of a plurality as a whole (and not of its individual members). The working definition of 'collective nouns' as singular forms translates the (strong) intuition that the content of these nouns is somehow simultaneously 'one' and 'many', and the connection between morphosyntactic and semantic properties of number and individuation.

Persson (1989) argues that animacy is a crucial criterion precisely because it is related to the parts' ability to have agency independently from the whole (as 'self-propelled entities'), or a high degree of individuation. Barker (1992) observes that they are compatible with plural, but not singular of-phrases. Pearson (2011) distinguishes two classes of collective nouns: 'collection nouns' such as stack, heap, bunch, bouquet, and collection, and 'committee nouns' such as committee, family, and team. She argues that the semantics of the latter has an intentional component that the former lacks, which accounts for their distinct behaviour in her various tests.

The paradoxical behaviour of collective NPs, sometimes behaving like setdenoting NPs and sometimes unlike them, has general consequences for any theory of their semantics. Approaches like Barker (1992) and Schwarzschild (1996), and to some extent Landman (1989), assume that collective nouns range over atomic entities, just as non-collective nouns like cat or semanticist. They can explain the 'one' facet, but need additional mechanisms to account for the 'many' properties. Approaches like that of Bennett [1974] treats group collectives as set-denoting, 
just like coordinated NPs and referential plural NPs. More recently, Kratzer (2001, 2008), Pearson (2011), Magri (2012) and de Vries (2013, 2015) have revived the set approach, providing new evidence for the plural nature of collective NP denotations, which they claim cannot be accounted for under an atomic account (ibid: 14-16).

In sum, most linguist or philosopher scholars are conscious of the dual number nature of (group) collectives, which translates into some semantic and/or morphosyntactic properties of plurals (or the 'many' lenses), but also into those of singulars (or the 'one' lens). It is then only through an explicit analysis of the kind of collective involved that the combination of these dual properties can be properly accounted for. More precisely, it is only when two kinds of individuation are identified as necessary and separate in representing the collective and its convergence (as in my AtomP and UnitP), that an appropriate account of the seemingly contradicting properties of 'one' and 'many' becomes available.

In the next two subsections, I turn to other sorts of 'collectives' described in the literature, involving group numerals in Czech, or 'collectivizers'/aggregates in Italian, in order to enlarge the range of crosslinguistic variation that convergence may apply to.

\subsection{Czech group numerals}

Grimm \& Dočekal (2017) analyse complex numerals in Czech, such as those found in (87), compared to simple numerals, exemplified in (88):

(87) troj-ice námořníků

three.ICE sailors.GEN

'A group of three sailors'

(88) tři námořníci

three sailors

'Three sailors'

In contrast with simple numerals in (88), complex numerals derived with -ice in (87) obtain a group interpretation, such as "group of three sailors", and are then termed group numerals (note that they apply only to animate nouns).

They then argue that Krifka's (1995) framework can be successfully used to treat cases of basic nominal semantics, as well as taxonomic numerals in Czech (with some minor modifications). But to cope with data arising from group numerals, more substantial extensions are required, and there is a need to enrich the system with groups in the sense of Landman (1989). ${ }^{34}$

34. Taxonomic numerals are roughly numerals that count kinds, they are formed with the suffix -oji, and their interpretation includes 'kind', or subkinds, as in the following construction:

(i) dv-ojí syrý two-OJI cheese 'Two kinds of cheese' 
Indeed, Krifka (ibid) does provide a method to analyse certain types of group nouns, such as herd, by making use of measure functions. As shown in (89), the measure function counts groups in the same way it counts atomic objects:

(89) $\llbracket$ three herds of cows $\rrbracket=\lambda x[R(x ;$ Cow $) \wedge$ Herd $($ Cow; $x)=3]$

But derived group numerals in Czech require a distinct analysis because counting with the aid of group numerals involves counting both the wholes and the parts. Thus, in (90), the suffix -ice (forming the group numeral) assigns a cardinal value to the members of the groups (troj-ice mužu 'a group of three men'), which themselves can be counted by $d v e$ 'two':

(90) dvě troj-ice mužu

two three-GROUP men.GEN

'Two groups of three men'

According to the authors, an analysis of these complex numerals will need a semantics which both (a) groups objects (for the purpose of counting groups) and (b) counts the number of objects in the group. The solution proposed is to augment the schema of Krifka with the group shifting operator of Landman (1989). The suffix -ice is then analysed as the head noun of the phrase taking the genitive argument mužu 'men', forming the group, which first combines with a number $n$, feeds the OU (object unit) operator, and then the property P provided by the argument. The application of troj- 'three' and then muž $u$ to -ice results in the meaning of 'a group of three men', as in (91) and (92); (ibid: 31-32): ${ }^{35}$

(91) $\llbracket$-ice $=\lambda \mathrm{n} \lambda \mathrm{P} \lambda \mathrm{x}[\uparrow(\mathrm{P}(\mathrm{x})) \wedge \mathrm{OU}(\mathrm{P} ; \mathrm{x})=\mathrm{n}]$

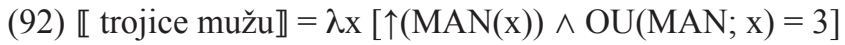

The outcome is fully countable, designating a singular in the domain of groups. The meaning given in (92) can itself be pluralized or counted by means of cardinal numbers, as in (90), where both the group and the single members are counted. Alternatively, one can view the grouping as applying to the numeral itself, rather than its nominal complement, i.e. to $n$ (for cardinal number, 3 ), rather than $N$ (for the noun MAN). If this is so, then a distinction can be made between the two countings. In one case, OU are atoms, in the other case, OU are unities. At any rate, there is a convergence in some sense in counting both, as pointed out by the authors, a

Other cases of complex numerals in Czech are aggregate numerals, which are formed with the suffix -oje, and designate 'collections', or rather entities that are 'connected' or come together, like 'shoes' in the following example:

(ii) dv-oje boty

two-OJE shoe.PL

'Two pairs of shoes'

See below fn. 37 for more on aggregates in Czech.

35. I have changed their dvojice to trojice, and 'sailors' to 'men', to make the analysis minimal. 
quite appealing result, although its routes may be different, depending on whether the grouping applies to $n$, or to $N .^{36}$

\subsection{Italian aggregates}

Franco, Baldi \& Savoia (2020) analyse Italian collectivizers as devices turning count (or mass) nouns into collectives, which are in a sort of complementary distribution with singulatives (or their mirror image), building a unitary item out of a set), and that the same morphology employed to convey a singulative meaning (evaluative and gender shift) is used also for collectivization purposes (basically like what happens in Arabic). These collectivizers are of different types, typically along the derivational/inflectional divide, although they have in common that they possess the 'aggregate value' at various levels of structure; see Chierchia (1998), Acquaviva (2008), and Manzini \& Savoia (2017). To give an example, the feminine - $a$ in Italian (and more generally Romance) consistently implies an [aggregate] interpretation, whereby - $a$ plurals correspond to "a set whose members are rather more like parts of whole than like individuated atoms". As shown with the nominal items in (93), basically found in Acquaviva (ibid: 126), the - $a$ plural (or aggregate) can be differentiated from the $-i$ plural by associating with the former the property of [aggregate]:

(93) a. bracci-o 'arm'; $\rightarrow$ bracci-a 'pair of arms'; $\rightarrow$ bracc-i 'branches'

b. dit-o 'finger'; $\rightarrow$ dit-a 'set of human fingers'; $\rightarrow$ dit- $i$ 'fingers'

c. cervell-o 'brain'; $\rightarrow$ cervell-a 'complex of brain'; $\rightarrow$ cervell- $i$ 'brains

d. mur-o 'wall'; $\rightarrow$ mur-a 'walls of a building'; $\rightarrow$ mur- $i$ 'walls'

The aggregate is analysed as (94), while the plural is analysed as in (95), for the pair bracci-a/bracc-i (Franco et al. ibid: 12):

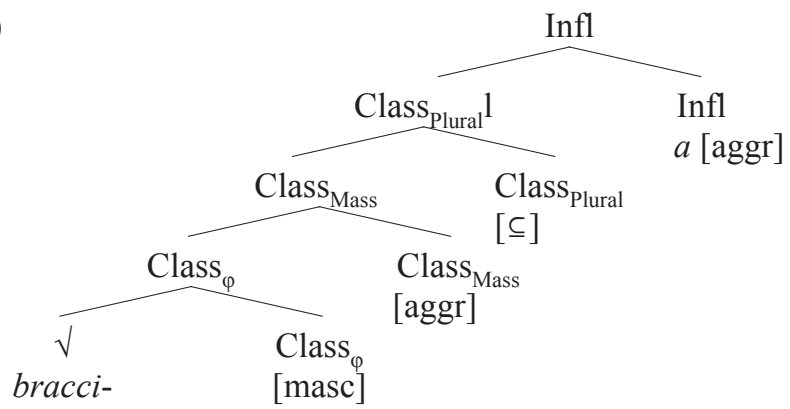

36. The distinction may be necessary to differentiate between the structures of simple numerals that count individuals and those of group nominals that count groups of individuals, as in (88) and (90) above. As I suggested, the group numeral may be grouping the number $\mathrm{n}$, rather than the nominal $\mathrm{N}$ (as the semantics in (92) states), although a form of 'group' agreement between the numeral and the nominal must be postulated whatever option is taken. For elaboration on syntactic numeral structures, see Kayne (2005), Fassi Fehri (2018, Ch 3), and Zabbal (2005), among others. 


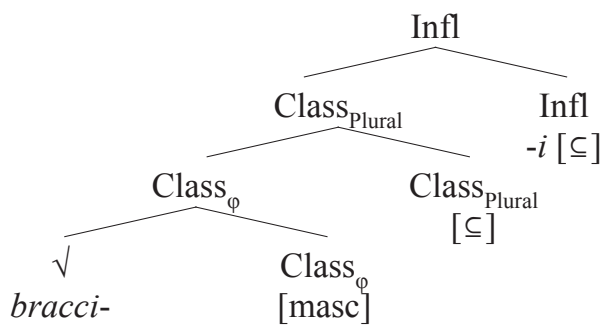

Described as such, the Italian collective seems also to present a case of Num/Gen convergence $(\mathrm{Gen}=$ Class here), although it remains to be seen what are the subtle properties of the degree of cohesiveness (or connectedness) that makes the collectizer less productive than the Arabic plurative. ${ }^{37}$

\subsection{Further syntax}

\subsubsection{Is the broken plural different?}

Attempts have been made to differentiate the sound/broken plural forms by associating them with distinct syntax and meanings. For example, one apparent descriptive characteristic of the broken plural is its lack of (overt) morphological gender (of the singular), compared to the external sound plural noun which normally manifests gender, suggesting that the sound plural nominal sequence is morphologically more complex than the broken one:

(96) kaatib (-at) 'writer (fem)' $\rightarrow$ kuttab 'writers'

(97) kaatib-at 'writer-FEM; female writer' $\rightarrow$ kaatib-aat 'writer-FEM.PL; female writers'

However, this line of thought is contradicted by the behaviour of broken plurals with (low) numerals. With the latter, the numeral varies in gender (in a 'polar' manner) depending on the gender of the counted noun. This is clearly seen in the variation in gender already found in (14) to (16), where the numeral agrees (in a reverse way) with the singular (rather than the plural) in gender. If so, then the broken plural is not devoid of gender. Moreover, it cannot be assimilated to a

37. Likewise, Grimm \& Dočekal (ibid) analyse Czech aggregates, based on a semantics integrating a topological extension of mereology. The derivational suffix $-i$ in Czech only applies to a restricted set of nouns, aggregate (derived mass) nouns, which refer to 'clustered' individuals, such as list $i$ 'foliage', a connected cluster of leaves. Then unlike typical noncountable nouns such as water, which allow contextual shifts to countable uses by adding a contextually specified measure function which counts units, $-i$ derived nouns resist contextual shifts to countable uses, since the OU operator is already part of the denotation (ibid: 36 ). If so, then Czech demonstrates that aggregates can be counted in their own right, implicating object internal units, in a manner similar, though distinct from groups, suggesting that many more noun types need to be accounted for, as far as the theory of countability is concerned. 
'gender' or 'classifier', leaving only the sound plural for Num or \#. The situation gets more complex when the plurative enters into the picture. A finer syntax of broken plurals can be shown to be flexible, in the sense that they can be generated under $n$ (or Gen), AtomP, UnitP, or NumP.

Within the category of 'plural', Arab grammarians traditionally draw a distinction between a 'plural of paucity', jam S l-qill-at (referring to quantity from three to ten), and jam l-katr-at, a 'plural of many', 'multal plural' (Ojeda 1992) (referring to a quantity more than ten). However, such a distinction (which applies only to broken plurals) is rather illusory in practice when Modern Standard Arabic is considered, and to what extent it has ever been real is undecided (Ferrando 2006).

\subsubsection{Syntactic projections}

A significant body of literature converges on the idea that Number is found at many levels or projections of structures, starting earlier with structuring the scale of (in) dividuation of entities or events, then quantities, measurements, event complexes, or temporal composition. Due to the huge literature on the various ontologies and domains, I will limit myself here to sketch only some properties of Number projections. For concreteness' sake, I will assume basically the architecture given by Acquaviva $(20017,2018)$ for the nominal domain, and that Borer's DivP is split up into two distinct projections, AtomP and UnitP. A rather simple representation of the DP structure is then as in (98): ${ }^{38}$

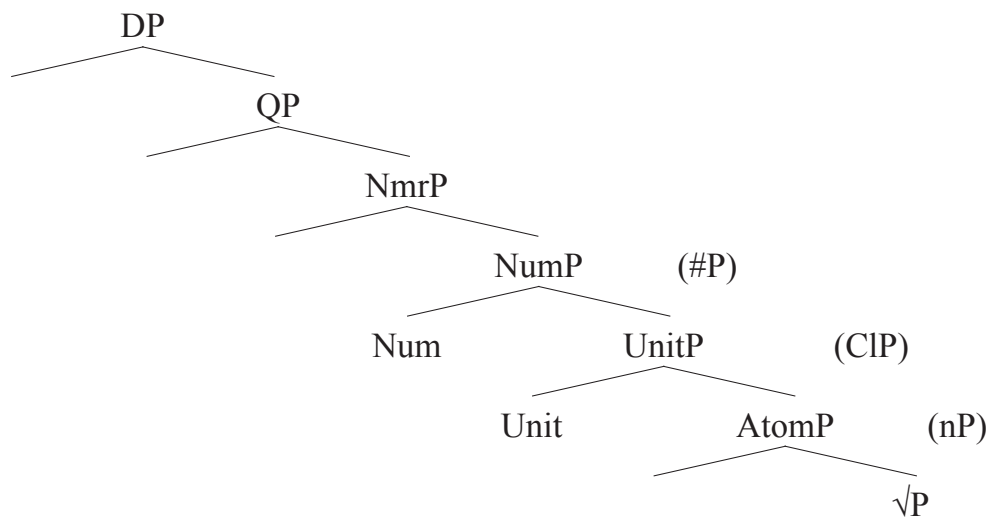

38. DP is the locus of reference, deixis, definiteness, and can be split into DP and KP to provide a special location for case. The projection nP, headed by $n$ (Marantz's 1997 categorizer, the existence of which is disputed by Borer 2005, 2013 and Adger 2013) can be introduced over $\sqrt{\mathrm{P}}$. Inspired by Harbour (2014), Acquaviva (2018) distinguishes a $n$ functor, notated $[\sqrt{ }]_{n}$, which names an entity type $e$, and is above $\sqrt{ }$, from a higher $\mathrm{P} \Sigma$ functor, the property of sums, which introduces variable, and creates lattice. For lack of space, I will not discuss these elaborations in detail. NmrP and QP are placed here as separate projections for numerals and quantifiers, as well as NumP or \#P (the locus of quantity or Number). An alternative that fuses NmrP and \#P is possible (see Borer 2005). For even more granular functional projections in the DP, as well as the clause structure, see Rizzi \& Cinque (2016). 
This structure is given only for the sake of visualizing how the entire architecture of the DP is designed. Other qualifications assumed are quite standard (see Acquaviva 2017, 2018, and Fassi Fehri 2018, for further detail and motivation). The central idea is that Number and Individuation are not just about atomicity; they are also about unity. Both contribute somehow to 'dividing reference' in the sense of Quine (1960), and intersect with Div in Borer (2005), although, my system is less 'coarse'. Not only are individuals born or built in the grammar as atoms (or as the bottom parts of 'division'), but they can also built as units, or unities (possibly assembling individual atoms to form a unit or unity, or 'refining' a potential sum, to built a unit from it).

\section{Summary and conclusion}

In this article, I described a specific morpho-syntactic mechanism of Number and Individuation (or Gender) convergence in the Arabic plurative, and more generally in groups and collectives in some other languages, including group numerals in Slavic. I argued that plurative and singulative constructions involve convergence of atomic and unity specifications, projected as atomP and unitP. This convergent complexity extends to other groups and collectives. It is shown that simple (nonconvergent) analyses of pluratives and groups can hardly be adequate. The analysis, which is morphosyntactically implemented, and interfacted with semantics, comes out as expected given the significant body of literature calling for binary division of individuation ingredients, but also for an appropriate theory of groups, other collectives, or interpretations of distinct pluralities. The proposed analysis accounts naturally for properties of these entities being 'one' and 'many' at the same time, or at different times, depending on perspectives. One would hope that the general theory of Number and Individuation integrate on principled bases both singularplural patterns, singulative-collective patterns, groups, aggregates, or other collectives, found in many languages, although in very different flavours.

\section{References}

Acquaviva, P. 2008. Lexical Plurals. Oxford: Oxford University Press.

Acquaviva, P. 2015. Singulatives. In P. Müller, I. Ohnheiser, S. Olsen \& F. Rainer (eds.). Word-Formation: An International Handbook of the Languages of Europe, 1173-1183. Berlin: de Gruter Mouton.

Acquaviva, Paolo. 2017. Number in Language. Oxford Research Encyclopedia in Linguistics, 56 pp. [online]. Available at: <https://www.oxfordbibliographies.com/ view/document/ obo-9780199772810/obo-9780199772810-0135.xml> [Accessed: September, 7, 2018]

Acquaviva, P. 2018. Categorization as noun construction. Gender, number, and entity types. In E. Mathieu, M. Dali \& G. Zareikar (eds.). Gender and Noun Classification, 41-63. Oxford: Oxford University Press.

Adger, D. 2013. A Syntax of Substance. Cambridge, MA: MIT Press.

Aikhenvald, A. 2000. Classifiers: A Typology of Noun Categorization Devices. Oxford: Oxford University Press. 
Allan, K. 1977. Classifiers. Language 53: 285-311.

Arsenijević, B. 2006. Partitivity and reference. In J. Dotlacil \& B. Gehrke (eds.). Proceedings of the Second Syntax AIO Meeting, 48-64.

Arsenijević, B. 2016-8. Gender, like classifiers, specifies the type of partition: evidence from Serbo-Croatian. University of Potsdam \& University of Niš manuscript.

Astarabaadii, R. (12th c.) [1979]. Sarh al-Kaafiyyah. Beyrouth: Daar al-kutub al-ilmiyyah.

Bale, A. \& Coon, J. 2014. Classifiers are for Numerals, Not for Nouns: Consequences for the Mass/Count Distinction. Linguistic Inquiry 45(4): 695-707.

Bale, A., Coon, J. \& López, N. 2019. Classifiers, partitions, and measurements: Exploring the syntax and semantics of sortal classifiers. Glossa 4(1): 1-30.

Barker, C. 1992. Group Terms in English: Representing Groups as Atoms. Journal of Semantics 9: 69-93.

Barner, D. \& Snedeker, J. 2005. Quantity judgements and individuation: Evidence that mass nouns count. Cognition 97: 41-66.

Beckwith, C. 2007. Phoronyms. Classifiers, Class Nouns, and the Pseudopartitive Construction. New York: Peter Lang.

Bennett, M. 1974. Some extensions of a Montague fragment of English. University of California doctoral dissertation.

Borer, H. 2005. Structuring sense. In Name only. Oxford: Oxford University Press.

Borer, H. \& Ouwayda, S. 2010. Men and their apples: Dividing plural and agreement Plural. HO. Beijing: GLOW in Asia VIII.

Boudelaa, S. \& Gaskell, G. 2002. A re-examination of the default system for Arabic plurals. Language and Cognitive Processes 17(3): 321-343.

Brugmann, K. 1897. The Nature and Origin of the Noun Genders in the Indo-European Languages. Lecture delivered at Princeton University.

Bunt, H. 1985. Mass Terms and Model-Theoretic Semantics. Cambridge: Cambridge University Press.

Carlson, G. 1977. Reference to kinds in English. PhD thesis. University of Mass at Amherst.

Champollion, L. \& Krifka, M. 2016. Mereology. In M. Aloni \& P. Dekker (eds.). The Cambridge Handbook of Formal Linguistics, 369-388. Cambridge: Cambridge University Press.

Cheng, L. \& Sybesma, R. 2005. Classifiers in four varieties of Chinese. In G. Cinque \& R. Kayne (eds.). The Oxford Handbook of Comparative Syntax, 259-292. Oxford: Oxford University Press.

Chierchia, G. 1998. Reference to kinds across languages. Natural Language Semantics 6: 339-405.

Chomsky, N. 1995. The Minimalist Program. Cambridge MA: MIT Press.

Corbett, G. 1991. Gender. Cambridge: Cambridge University Press.

Corbett, G. 2000. Number. Cambridge: Cambridge University Press.

De Belder, M. 2008. Size matters: towards a syntactic decomposition of countability. In N. Abner \& J. Bishop (eds.). Proceedings of the $27^{\text {th }}$ West Coast Conference on Formal Linguistics, 116-122. Somerville MA: Cascadilla Press.

De Vries, H. 2015. Shifting sets, hidden atoms: the semantics of distributivity, plurality and animacy. $\mathrm{PhD}$ thesis. Utrecht University. 
De Vries, H. 2019. Collective nouns. To appear in P. Cabredo Hofherr \& J. Doetjes (eds.). Oxford Handbook of Grammatical Number.

Dimmendaal, G. 1983. The Turkana language. Dordrecht: Foris.

Dixon, R. 1982. Where have all the adjectives gone? and other essays in semantics and syntax. Berlin: Mouton.

Fassi Fehri, A. 1988. Agreement, Binding, and Coherence. In M. Barlow \& C. Ferguson (eds.). Agreement in Natural Language, 107-158. Stanford: CSLI.

Fassi Fehri, A. 2003-4. Nominal classes and parameters across interfaces and levels, with a particular reference to Arabic. In Linguistic Variation Yearbook, 41-108. Amsterdam: John Benjamins, Vol. 4.

Fassi Fehri, A. 2012. Key Features and Parameters in Arabic Grammar. Amsterdam: John Benjamins.

Fassi Fehri, A. 2016. Semantic Gender Diversity and Its Architecture in the Grammar of Arabic. Brill's Journal of Afroasiatic Languages and Linguistics 8: 154-199.

Fassi Fehri, A. 2018. Constructing the Feminine to Mean. Gender, Number, Numeral, and Quantifier extensions in Arabic. New York: Lexington Books.

Fassi Fehri, A. \& Vinet, M.T. 2004. Distribution of number and classifier in Arabic and Chinese and parametrization. Linguistic Research. Rabat: IERA Publications, 9(2): 9-52.

Fassi Fehri, A. \& Vinet, M.T. 2007. Number and classifier distributions in Arabic and Chinese. In A. Zaenen, J. Simpson, T. King, J. Grimshaw, J. Maling \& C. Manning (eds.). Architectures, Rules, and Preferences, Variations on Themes by Joan Bresnan, 163-197. Stanford CA: CSLI.

Ferrando, I. 2006. The plural of paucity in Arabic and its actual scope. In S. Boudelaa (ed.). Perspectives on Arabic linguistics XVI, 39-62. Amsterdam: John Benjamins.

Franco, L., Baldi, B. \& Savoia, L. 2020. Collectivizers in Italian (and beyond). The interplay between collectivizing and evaluating morphology (and the Div paradox). Studia Linguistica 74(1): 2-41.

Gil, D. 1996. Maltese 'collective nouns': a typological perspective. Rivista di Linguistica 8: 53-87.

Gil, D. 2013. Numeral classifiers. In M. Dryer \& M. Haspelmath (eds.). The World Atlas of Language Structures online, Chapter 55. Berlin: Max Planck Digital Library.

Gillon, B. 1992. Towards a common semantics for English count and mass nouns. Linguistics and Philosophy 15: 597-640.

Gray, J. \& Gregor, T. 2019. Gender/number syncretism in Yelmek verbal suppletion. Ms. Australian National University \& ARC Centre of Excellence for the Dynamics of Language.

Greenberg, J. 1972. Numeral classifiers and substantival number. In Proceedings of the Eleventh Congress of Linguists, 17-37. Bologna: Sodeta editrice il Mulin.

Grimm, S. 2012. Number and Individuation. Ph. D. thesis. Stanford University.

Grimm, S. \& Dočekal, M. 2017. Counting Aggregates, Groups and Kinds: Countability from the Perspective of a Morphologically Complex Language. To appear. In Counting and Measuring Across Languages. Cambridge: Cambridge University Press.

Harbour, D. 2014. Paucity, abundance, and the theory of number. Language 90: 185-229. 
Harley, H. 2014. On the identity of roots. Theoretical Linguistics 40(3-4): 225-276.

Harley, H. \& Ritter, E. 2002. Person and number in pronouns: A feature-geometric analysis. Language 78: 482-526.

Haspelmath, M. \& Karjus, A. 2017. Explaining asymmetries in number marking: Singulatives, pluratives, and usage frequency. Linguistics 55(6): 1213-1235.

Hsieh, M.L. 2008. The internal structure of noun phrases in Chinese. Taipei: Crane Publishing Co.

Iljić, R. 1994. Quantification in Mandarin Chinese: Two markers of plurality. Linguistics 32: 91-116.

Iljić, R. 2001. The problem of the suffix -men in Chinese Grammar. Journal of Chinese Linguistics 29(1): 11-67.

Keenan, C. 2013. A Pleasant Three Days in Philadelphia: Arguments for a Pseudopartitive Analysis. University of Penn Working Papers in Linguistics 19: 87-96.

Kramer, R. 2015. The Morphosyntax of Gender. Oxford: Oxford University Press.

Kramer, R. 2018. A novel kind of gender syncretism. In E. Mathieu, M. Dali \& G. Zareikar (eds.). Gender and noun classification, 159-183. Oxford: Oxford University Press.

Kratzer, A. 2001. The event argument. [online]. $<$ http://semanticsarchive.net/ $>$ Archive/ GU1NWM4Z/.

Kratzer, A. 2008. On the plurality of verbs. In J. Dölling, T. Heyde-Zybatow \& M. Schäfer (eds.). Event Structures in Linguistic Form and Interpretation, 269-299. Berlin: de Gruyter Mouton.

Krifka, M. 1989. Nominal reference, temporal constitution and quantification in event Semantics. In R. Bartsch, J. van Benthem \& P. von Emde Boas (eds.). Semantics and Contextual Expression, 75-115. Dordrecht: Foris.

Krifka, M. 1995. Common nouns in Chinese and in English. In G. Carlson \& F. Pelletier (eds.). The Generic Book, 398-411. Chicago: University of Chicago Press.

Krifka, M. 2004. Bare NPs: Kind-referring, indefinites, both, or neither? In R. Young \& Y. Zhou (eds.). Proceedings of Semantics and Linguistic Theory (SALT) XIII, 183-203. Cornell: CLC Publications.

Krifka, M. 2013. Measuring and Counting in the Nominal and the Verbal Domain. Workshop on Countability. Universität of Düsseldorf.

Landman, F. 1989. Groups. Linguistics and Philosophy 12(5): 559-605; 12(6): 723-744.

Landman, F. 2006. On the mass-count distinction. Ms. Tel Aviv University.

Leisi, E. 1971. Der Wortinhalt. Seine Struktur im Deutschen und im Englischen, 4th ed. Heidelberg: Quelle \& Meyer.

Leiss, E. 1994. Genus und Sexus, Kritische Anmerkungen zur Sexualisierung von Grammatik. Linguistische Berichte 152: 281-300.

Link, G. 1983. The logical analysis of plurals and mass terms: A lattice-theoretical Approach. In R. Bauerle, C. Schwarze \& A. von Stechow (eds.). Meaning, Use, and Interpretation of Language, 303-323. Berlin: Mouton de Gruyter.

Link, G. 1998. Natural Language and Algebraic Semantics. Stanford CA: CSLI.

Lowenstamm, J. 2008. On Little n, V, and Types of Nouns. In J. Hartmann, V. Hegedüs \& H. van Riemsdijk (eds.). Sounds of Silence, 105-144. Amsterdam: Elsevier.

Lučić, R. 2015. Observations on Collective Numerals in Standard Croatian. Journal of Slavic Linguistics 23(1): 3-31. 
Magri, G. 2012. Collective nouns without groups. In E. Cohen (ed.). Proceedings of IATL 27, MIT Working Papers in Linguistics, 183-202.

Manzini, R. \& Savoia, L. 2017. Gender, number and inflectional class in Romance. In J. Emonds \& M. Janebova (eds.). Language Use and Linguistic Structure, 263-282. Olomouc: Palacky University Press.

Marantz, A. 1997. No escape from syntax. UWPL 4: 201-225.

Marantz, A. 2001. Phases and Words. Ms. New York University.

Mari, A., Beyssade, C. \& Del Prête, F. 2013. Introduction. In A. Mari, C. Beyssade \& F. Del Prête (eds.). Genericity, 1-92. Oxford: Oxford University Press.

Mathieu, E. 2012. Flavors of division. Linguistic Inquiry 43: 650-679.

McCarthy, J. \& Prince, A. 1990. Foot and word in prosodic morphology: The Arabic broken plural. Natural Language and Linguistic Theory 8: 209-283.

Meirav, A. 2003. Wholes, Sums and Unities. Dordrecht: Kluwer.

Mihatsch, W. 2015. Collectives. In P. Müller, I. Ohnheiser, S. Olsen \& F. Rainer (eds.). Word-Formation: An International Handbook of the Languages of Europe, 11831195. Berlin: de Gruter Mouton.

Mous, M. 2008. Number as an exponent of gender in Cushitic. Ms. RCLT. La Trobe \& Leiden University.

Nouwen, R. 2016. Plurality. In M. Aloni \& P. Dekker (eds.). The Cambridge Handbook of Formal Linguistics, 267-284. Cambridge: Cambridge University Press.

Ojeda, A. 1992. The semantics of number in Arabic. In C. Barker \& D. Dowty (eds.). SALT II, 303-325. Columbus: Ohio State University.

Ojeda, A. 1998-2005. The Semantics of Collectives and Distributives in Papago. Natural Language Semantics 6(3): 245-270.

Ojeda, A. \& Grivićić, T. 2005. The Semantics of Sero-Croatian Collectives. In O. Orgun and P. Sells (eds.). Morphology and the Web Grammar. Essays in Memory of Steven Lapointe, 225-240. Stanford: CSLI Publications.

Ouwayda, S. 2014. Where Number Lies. University of South California: PhD thesis.

Quine, W. 1960. Word and object. Cambridge, MA: MIT Press.

Pearson, H. 2011. A new semantics for group nouns. In M. Byram-Washburn, K. McKinney-Bock, E. Varis, A. Sawyer \& B. Tomaszewicz (eds.). Proceedings of the 28th West Coast Conference on Formal Linguistics, 160-168. Somerville, MA: Cascadilla Press.

Pelletier, F. 1979. Non-singular reference: Some preliminaries. In F. Pelletier (ed.). Mass Terms: Some Philosophical Problems, 1-14. Dordrecht: Kluwer Academic.

Pelletier, F. 2010. Mass Terms: A Philosophical Introduction. In F. Pelletier (ed.). Kinds, Things, and Stuff. Mass Terms and Generics, 123-131. Oxford: Oxford University Press.

Persson, G. 1989. On the semantics of collective nouns in English. In B. Odenstedt \& G. Persson (eds.). Papers in honour of Mats Ryden on the occasion of his sixtieth birthday, 179-195. Stockholm: Almqvist \& Wiksell International.

Ratcliffe, R. 2011. Number. In K. Versteegh (ed.). Encyclopedia of Arabic Language and Linguistics, 439-447. Leiden: Brill, Vol. 3.

Rijkhoff, J. 2002. The Noun Phrase. Oxford: Oxford University Press.

Ritter, E. 1991. Two functional categories in noun phrases: Evidence from Modern Hebrew. In S. Rothstein (ed.). Perspectives on Phrase Structure. Syntax and Semantics 25, 37-62. New York: Academic Press. 
Rizzi, L. \& Cinque, G. 2016. Functional Categories and Syntactic Theory. Annual Review of Linguistics 2: 139-163.

Roman, A. 1990. De l'accord et du pseudo-accord du féminin en arabe. Annales Islamologiques 25: 27-56.

Rothstein, S. 2010. Counting and the mass/count distinction. Journal of Semantics 27: 343-397.

Rullmann, H. \& You, A. 2006. General number and the semantics and pragmatics of indefinite bare nouns in Mandarin Chinese. In K. von Heusinger \& K. Turner (eds.). Where Semantics Meets Pragmatics, 175-196. Amsterdam: Elsevier.

Sauerland, U. 2003. A new semantics for number. In R. Young \& Y. Zou (eds.). SALT XIII, 258-275. Ithaca, New York: CLC Publications.

Scha, R. 1981. Distributive, collective and cumulative quantification. In J. Groenendijk, T. Janssen \& M. Stokhof (eds.). Formal methods in the study of language, 483-512. Amsterdam: Mathematisch Centrum, Vol. 2.

Scontras, G. 2014. The Semantics of Measurement. Harvard University dissertation.

Seifart, F. 2009. Towards a typology of unitization: Mirana noun classes compared to numeral classifiers and singulatives. Ms. Leipzig: Max Planck Institute for Evolutionary Anthropology.

Seifart, F. 2010. Nominal classification. Language and Linguistics Compass 4(8): 719736.

Selkirk, E. 1977. Some remarks on noun phrase structure. In P. Culicover, T. Wasow \& A. Akmajian, eds. Formal Syntax, 285-316. New York: Academic Press.

Sibawayhi, Amr. (8 ${ }^{\text {th }}$ c.) [1938)]. al-Kitaab. 2 vol. Cairo: Buulaaq.

Stickney, H. 2009. The Emergence of DP in the Partitive Structure. University of Mass at Amherst Doctoral dissertation.

Sudo, Y. \& Spathas, G. 2016. Natural Gender and interpretation in Greek. Ms. UCL \& Universität Stuttgart \& Humboldt Universität zu Berlin.

Suyuutii, J. (15 th c.) [1998]. Al-Muzhir fii Suluum al-lugah al-Sarabiyyah. 2 Vol. Beirut: Dar al-kutub al-Silmiyyah.

Schwarzschild, R. 1996. Pluralities. Dordrecht: Kluwer.

Unterbeck, B. 2000. Gender: New light on an old category. In B. Unterbeck, M. Rissanen, T. Nevalainen \& M. Saari (eds.). Gender in grammar and cognition, xv-xxv. Berlin: Mouton de Gruyter.

Wagiel, M. 2018. Grammatical Gender Meets Classifier Semantics: Evidence from Slavic Numerals. FASL. Michigan Slavic Publications, 27: 418-440.

Wechsler, S. \& Zlatić, L. 2003. The Many Faces of Agreement. Stanford: CSLI Publications.

Wiese, H. 2012. Collectives in the intersection of mass and count nouns: A crosslinguistic account. In D. Massam (ed.). Count and Mass Across Languages, 54-74. Oxford: Oxford University Press.

Wiltschko, M. 2012. Decomposing the mass/count distinction: In D. Massam (ed.). Count and mass across languages, 146-171. Oxford: Oxford University Press.

Wright, W. 1971. A grammar of the Arabic language. Cambridge: Cambridge University Press. Translated from Caspari 1859, with revisions and annotations.

Yi, B.U. 2009. Chinese classifiers and count nouns. Journal of Cognitive Science 10: 209-225. 
Zabbal, Y. 2002-5. The semantics of number in the Arabic noun phrase. MA Thesis. University of Calgary.

Zabbal, Y. 2005. The Syntax of Numeral Expressions. Ms. University of Mass at Amherst.

Zhang, N. 2013. Classifier Structures in Mandarin Chinese. Berlin: Mouton. 